\title{
Biosensor for direct bioelectrocatalysis detection of nitric oxide using nitric oxide reductase incorporated in carboxylated single-walled carbon nanotubes/lipidic 3 bilayer nanocomposite
}

Filipa O. Gomes

Luísa B. Maia

Joana A. Loureiro

Maria Carmo Pereira

Cristina Delerue-Matos

Isabel Moura

José J. G. Moura

Simone Morais

\section{Abstract}

An enzymatic biosensor based on nitric oxide reductase (NOR; purified from Marinobacter hydrocarbonoclasticus) was developed for nitric oxide (NO) detection. The biosensor was prepared by deposition onto a pyrolytic graphite electrode (PGE) of a nanocomposite constituted by carboxylated single-walled carbon nanotubes (SWCNTs), a lipidic bilayer [1,2-di-(9Z-octadecenoyl)-sn-glycero-3-phosphoethanolamine (DOPE), 1,2-di-(9Z-octadecenoyl)-3-trimethylammonium-propane (DOTAP), 1,2-distearoyl-snglycero-3-phosphoethanolamine-polyethylene glycol (DSPE-PEG)] and NOR. NOR direct electron transfer and NO bioelectrocatalysis were characterized by several electrochemical techniques. The biosensor development was also followed by scanning electron microscopy and Fourier transform infrared spectroscopy. Improved enzyme stability and electron transfer $\left(1.96 \times 10^{-4} \mathrm{~cm} . \mathrm{s}^{-1}\right.$ apparent rate constant $)$ was obtained with the optimum SWCNTs/(DOPE:DOTAP:DSPE-PEG)/NOR) ratio of 4/2.5/4 ( $\mathrm{v} / \mathrm{v} / \mathrm{v})$, which biomimicked the NOR environment. The PGE/[SWCNTs/(DOPE:DOTAP:DSPEPEG)/NOR] biosensor exhibited a low Michaelis-Menten constant $(4.3 \mu \mathrm{M})$, wide linear range $(0.44-9.09 \mu \mathrm{M})$, low detection limit $(0.13 \mu \mathrm{M})$, high repeatability $(4.1 \% \mathrm{RSD})$, reproducibility ( $7.0 \%$ RSD), and stability (ca. 5 weeks). Selectivity tests towards Larginine, ascorbic acid, sodium nitrate, sodium nitrite and glucose showed that these compounds did not significantly interfere in NO biosensing $(91.0 \pm 9.3 \%-98.4 \pm 5.3 \%$ recoveries). The proposed biosensor, by incorporating the benefits of biomimetic features of the phospholipid bilayer with SWCNT's inherent properties and NOR bioelectrocatalytic activity and selectivity, is a promising tool for NO.

\section{Keywords}

Direct electron transfer

Enzymatic biosensor

Nitric oxide reductase 


\section{Introduction}

Nitric oxide reductase (NOR) is a key enzyme in the denitrification pathway, where

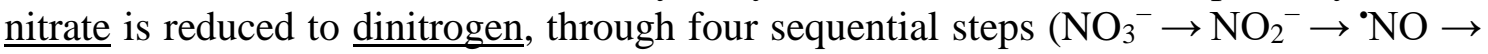
$\mathrm{N}_{2} \mathrm{O} \rightarrow \mathrm{N}_{2}$ ), catalyzed by specific metalloenzymes. NOR catalyzes the reduction of nitric oxide radical (NO) to nitrous oxide $\left(\mathrm{N}_{2} \mathrm{O}\right)$ in a two-electron/proton reaction [1]. This enzyme is a membrane-bound metalloprotein containing two subunits: the NorC subunit harbors one heme $c$ and responsible for the electron transfer from the physiological electron donor to the catalytic subunit; the NorB subunit, the catalytic subunit, is constituted by two hemes $b$, heme $b$ and heme $b_{3}$, and one non-heme iron, $\mathrm{Fe}_{\mathrm{B}}$; heme $b_{3}$ and $\mathrm{Fe}_{\mathrm{B}}$ are bridged by a $\mu$-oxo/hydroxo group and, together, form the catalytic diiron center (Fig. 1) [2]. NOR can be isolated from different organisms, including denitrifying bacteria, such as Paracoccus denitrificans, Pseudomonas stutzeri, Pseudomonas aeruginosa or Marinobacter hydrocarbonoclasticus.

\section{NorB}
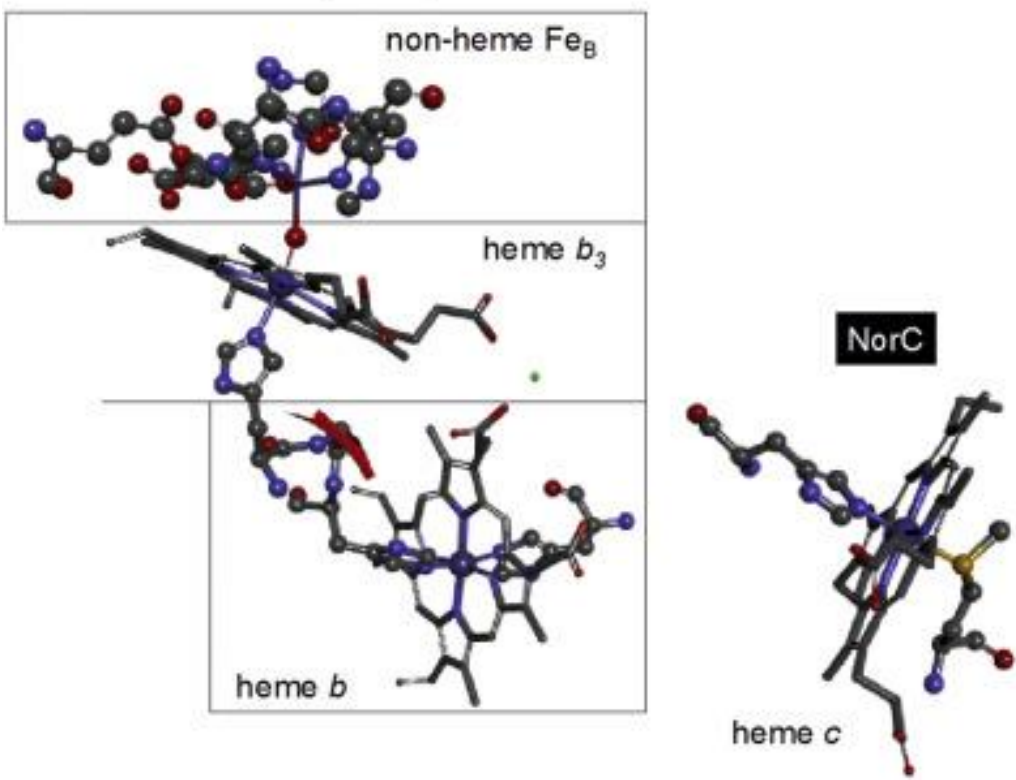

1. Download : Download high-res image (117KB)

2. Download : Download full-size image

Fig. 1. Marinobacter hydrocarbonoclasticus NOR redox-active centers. NOR is a heterodimeric enzyme, containing a NorC subunit, that harbors one heme $\mathrm{c}$, and a Nor $\mathrm{B}$ subunit (the catalytic subunit), that holds one heme $b$, one heme $b_{3}$, and one non-heme iron, $\mathrm{Fe}_{\mathrm{B}}$; heme $b_{3}$ and $\mathrm{Fe}_{\mathrm{B}}$ are bridged by a $\mu$-oxo/hydroxo group and, together, form the catalytic diiron center. Structure adapted from Protein Data Base (code 3O0R).

In recent decades, NO has been under a tremendous scrutiny due to the environmental importance of the denitrification pathway [ $\underline{3}]$ and to the involvement of NO in a plethora of biological events in all forms of life (cell differentiation, regulation of blood flow, heart and neurodegenerative diseases, among many others) [4]. NO reacts rapidly with several biological compounds, including $\mathrm{O}_{2}$, heme proteins (e.g., hemoglobin), thiols (e.g., cysteine residues, glutathione), and other radicals (e.g., superoxide anion radical) and, as a consequence, has a short half-life, which has been reported to be in the range of 5-15 s 
[5]. Moreover, NO exists at a broad range of concentrations, from $\mathrm{pM}$ to $\mu \mathrm{M}$. These NO features make its detection and quantification a challenging task. Therefore, appropriate analytical techniques to study NO should have a wide working range and rapid response times []. In this scenario, third-generation electrochemical biosensors are the approach of choice for direct, real-time, selective and sensitive measurements, for both in vitro and in vivo studies of NO metabolism and homeostasis [7]. Moreover, third-generation biosensors are a powerful tool to study the catalytic mechanisms of redox enzymes [[8], [9], [10]].

Previously architected enzymatic biosensors for NO detection have been mainly based on peroxidases (horseradish peroxidase (HRP) and microperoxidase (MP)) $[\underline{11}, \underline{12}]$. In this work, a new biosensor using the NOR from Marinobacter hydrocarbonoclasticus is described. This enzyme has been the subject of a very limited number of studies [[13], [14], [15], [16], [17]], where it was directly immobilized onto a graphite electrode, with the only goal of characterizing its direct electrochemical behavior and catalytic mechanism.

The major challenge for developing enzymatic biosensors is to succeed in the stabilization of the enzyme on the solid support. For this reason, carbon nanotubes (CNTs) have been the most reported nanomaterials, because they keep high biological activity of the enzyme, decrease the redox potential of the reaction and increase the sensitivity, stability and lifetime of the biosensor [[18], [19], [20], [21]]. Considering that NOR is a membrane-bound enzyme, a lipidic bilayer (liposomes composed by different phospholipids) is an interesting alternative for its immobilization, since it could mimic the cellular NOR environment and help to maintain the enzyme active conformation. Lipidic structures have been used in several systems to amplify the signal intensity, with clear benefits on the reached sensitivity and detection limits [22,23]. Anionic and zwitterionic phospholipids [1-hexadecanoyl-2-(9Z-octadecenoyl)-sn-glycero-3phosphocholine (POPC); N-glutaryl-phosphatidylethanolamine (NGPE); 1,2dihexadecanoyl-sn-glycero-3-phospho-(1'-rac-glycerol) (sodium salt) (DPPG); 1hexadecanoyl-2-(9Z-octadecenoyl)-sn-glycero-3-phospho-(1'-rac-glycerol) (sodium salt) (POPG); 1,2-dimyristoyl-sn-glycero-3-phospho- (1-rac-glycerol) (DMPG); lyso-1heptadecanoyl-sn-glycero-3-phosphocholine (LPC)] and Langmuir-Blodgett films composed by arachidic acid have been the most tested for the development of enzymatic biosensors (Table 1); the only enzymes used on those studies were tyrosinase (Tyr), MP, monoamine oxidase B (MAO-B), HRP, acetylcholinesterase (AChE) and glucose oxidase (GOD). Still, the number of studies (Table 1) is very limited [[24], [25], [26], [27], [28], [29], [30]]. Cationic and other zwitterionic phospholipids, such as 1,2-di-(9Zoctadecenoyl)-sn-glycero-3-phosphoethanolamine (DOPE), 1,2-di-(9Z-octadecenoyl)-3trimethylammonium-propane (DOTAP) and 1,2-distearoyl-sn-glycero-3phosphoethanolamine (DSPE) have not yet been tested for preservation, stabilization and immobilization of enzymes. Moreover, the insertion of hydrophilic polymers, such as polyethylene glycol (PEG), in the lipidic bilayer may help to avoid liposomes fusion, while promoting excellent biocompatibility, low immunogenicity and antigenicity for in vivo assays [31]. PEG is non-ionic, low fouling and possesses high solubility; PEG can be prepared with different molecular weights, influencing, in this way, the lipidic bilayer permeability [32]. Pegylated lipidic bilayer has been widely applied for drug delivery systems [31], but not yet applied in electrochemical enzymatic biosensors [33].

Table 1. Review of the reported enzymatic biosensors based on lipidic bilayer. 
Table 1

Review of the reported enzymatic biosensors based on lipidic bilayer.

\begin{tabular}{|c|c|c|c|c|c|c|c|c|}
\hline Transducer & Enzyme & Lipidic bilayer & Analyte & $\begin{array}{l}\text { Substrate/detected } \\
\text { species }\end{array}$ & $\begin{array}{l}\text { Linear range } \\
(\mu \mathrm{M})\end{array}$ & $\begin{array}{l}\text { Detection } \\
\text { limit }(\mu \mathrm{M})\end{array}$ & $\begin{array}{l}\text { Stability } \\
\text { (days;\%) }\end{array}$ & Ref. \\
\hline $\begin{array}{l}\text { Tin oxide doped } \\
\text { with indium }\end{array}$ & Tyrosinase & LB films & Antioxidants & Caffeic acid & $10-400$ & 1.98 & n.r. & {$[24]$} \\
\hline $\begin{array}{l}\text { Glassy carbon } \\
\text { electrode }\end{array}$ & Tyrosinase & LPC & $\begin{array}{l}\text { Phenolic } \\
\text { compounds }\end{array}$ & Phenol & $0.25 \times 10^{-3}-25$ & $\begin{array}{l}0.091 \times \\
10^{-3}\end{array}$ & $2.5 ; 91$ & {$[25]$} \\
\hline $\begin{array}{l}\text { Glassy carbon } \\
\text { electrode }\end{array}$ & Microperoxidase & DMPG & $\mathrm{H}_{2} \mathrm{O}_{2}$ & $\mathrm{H}_{2} \mathrm{O}_{2}$ & $2.0-450$ & 0.72 & $20 ; 91$ & {$[26]$} \\
\hline $\begin{array}{l}\text { Tin oxide doped } \\
\text { with indium }\end{array}$ & $\begin{array}{l}\text { Monoamine oxidase } \\
\text { B }\end{array}$ & DPPG/POPG & Dopamine & $\mathrm{H}_{2} \mathrm{O}_{2}$ & $1400-10,000$ & $860 \pm 16$ & n.r & [27] \\
\hline $\begin{array}{l}\text { Glassy carbon } \\
\text { electrode }\end{array}$ & $\begin{array}{l}\text { Horseradish } \\
\text { peroxidase }\end{array}$ & $\begin{array}{l}N, N^{\prime} \text {-bis(10-undecenyl)-2- } \\
\text { methylimidazolium bromide }\end{array}$ & $\mathrm{H}_{2} \mathrm{O}_{2}$ & $\mathrm{H}_{2} \mathrm{O}_{2}$ & $10-2300$ & 3.33 & $30 ; 97$ & {$[28]$} \\
\hline $\begin{array}{l}\text { Glassy carbon } \\
\text { electrode }\end{array}$ & Acetylcholinesterase & LPC & $\begin{array}{l}\text { Organophosphate } \\
\text { Pesticides }\end{array}$ & $\begin{array}{l}\text { Acetylthiocholine } \\
\text { chloride }\end{array}$ & $\begin{array}{l}0.25-1.75 \\
2.00-10.00\end{array}$ & $\begin{array}{l}0.68 \pm \\
0.076 \mu \mathrm{g} / \mathrm{L}\end{array}$ & $30 ; 85$ & [29] \\
\hline $\begin{array}{l}\text { Tin oxide doped } \\
\text { with indium }\end{array}$ & Glucose oxidase & $\mathrm{POPC} / \mathrm{NGPE} /$ cholesterol & Glucose & $\mathrm{H}_{2} \mathrm{O}_{2}$ & $19,600-107,100$ & 13,000 & n.r. & [30] \\
\hline $\begin{array}{l}\text { Graphite pyrolitic } \\
\text { electrode }\end{array}$ & $\begin{array}{l}\text { Nitric oxide } \\
\text { reductase }\end{array}$ & DOPE:DOTAP:DSPE-PEG & NO & NO & $0.44-9.09$ & 0.13 & $35 ; 83.5$ & $\begin{array}{l}\text { This } \\
\text { study }\end{array}$ \\
\hline
\end{tabular}

DMPG: 1,2-dimyristoyl-sn-glycero-3-phospho- (1-rac-glycerol); DOPE: 1,2-di-(9Zoctadecenoyl)-sn-glycero-3-phosphoethanolamine; DOTAP: 1,2-di-(9Z-octadecenoyl)3-trimethylammonium-propane; DPPG: Dipalmitoyl phosphatidyl glycerol; DSPE-PEG: 1,2-distearoyl-sn-glycero-3-phosphoethanolamine - polyethylene glycol; LB: LangmuirBlodgett; LPC: L- Phosphocholine; NGPE: N-glutaryl-phosphatidylethanolamine; POPC: 1-Palmitoyl-2- oleoyl-sn-glycero-3-phosphocholine; POPG: Palmitoyl phosphatidyl gliceral; n.r. - not reported.

Therefore, in this study, and for the first time, NOR was combined with carboxylated single-walled carbon nanotubes (SWCNTs) and the lipidic bilayer DOPE:DOTAP:DSPE-PEG to modify a pyrolytic graphite electrode (PGE) and to develop a novel and sensitive third-generation electrochemical biosensor for NO detection.

\section{Materials and methods}

\subsection{Reagents}

SWCNTs-COOH, chloroform $\left(\mathrm{CHCl}_{3}\right.$, p.a.), $N, N$-dimethylformamide (DMF; 99\%), HEPES buffer $(10 \mathrm{mM}, \mathrm{pH} 7.4)$, 2-phenylethanol (PE; $\geq 99.0 \%)$, potassium hexacyanoferrate (II) trihydrate $\left(\mathrm{C}_{6} \mathrm{FeK}_{4} \mathrm{~N}_{6} .3 \mathrm{H}_{2} \mathrm{O} ; \geq 99 \%\right)$, potassium hexa-cyanoferrate (III) $\left(\mathrm{C}_{6} \mathrm{FeK}_{3} \mathrm{~N}_{6} ; \geq 99 \%\right)$ and $\underline{\mathrm{L} \text {-Arginine }}(\geq 98 \%)$ were purchased from Sigma-Aldrich (Steinhein, Germany). Sulfuric acid $\left(\mathrm{H}_{2} \mathrm{SO}_{4} ; 96 \%\right)$, ethanol (EtOH; 99.5\%) and ndodecyl- $\beta$-D-maltoside (DDM) were obtained from Panreac (Barcelona, Spain). DOTAP (chloride salt, $698.54 \mathrm{~g} \mathrm{~mol}^{-1}$; >99\%), DOPE $\left(744.03 \mathrm{~g} \mathrm{~mol}^{-1} ;>99 \%\right)$ and DSPE-PEG (1,2-distearoyl-sn-glycero3-phosphoethanolamine-N-[amino(polyethylene glycol)-2000] (ammonium salt, $2790.49 \mathrm{~g} \mathrm{~mol}^{-1}$; > 99\%) were purchased from Avanti Polar Lipids (Alabama, USA). Di-potassium hydrogen phosphate $\left(\mathrm{K}_{2} \mathrm{HPO}_{4}\right.$, p.a.) and potassium dihydrogen phosphate $\left(\mathrm{KH}_{2} \mathrm{PO}_{4}\right.$, p.a.) were used to prepare phosphate buffer $(100 \mathrm{mM}$, pH 6.0); they were bought from Riedel-de-Haën (Germany) as well as potassium hydroxide (p.a.), ascorbic acid (p.a.) and sodium nitrate (p.a.). Sodium nitrite (p.a.) was acquired from M\&B and d-glucose anhydrous (ACS) from Scharlau (Barcelona, Spain).

NO solutions of different concentrations were prepared by dilution from a buffer stock solution of $100 \mu \mathrm{M}$ [34] prepared by bubbling a 5\% NO/95\% He gas mixture (Air Liquid, Portugal) into phosphate buffer $100 \mathrm{mM} \mathrm{pH} \mathrm{6.0.} \mathrm{All} \mathrm{solutions} \mathrm{and} \mathrm{stock} \mathrm{were} \mathrm{prepared}$ immediately before being used. 
Ultrapure water obtained from a Millipore water purification system (18 M $\Omega$, Milli-Q, Millipore, Molsheim, France) was used in all experiments.

\subsection{NOR purification}

NOR is not commercially available and it was purified from membrane extracts of Marinobacter hydrocarbonoclasticus grown anaerobically as described by Prudêncio et al. [35]. The NOR fractions were pooled, concentrated and equilibrated in $100 \mathrm{mM}$ potassium phosphates $\mathrm{pH} 7.0,0.02 \%(w / v)$ DDM, 0.01\% $(v / \mathrm{v}) \mathrm{PE}[35]$; further details are presented in Supplementary Material. NOR purity was assessed by its UV-visible spectrum (UV 1800-Shimadzu, 250-800 nm, Germany) and by sodium dodecyl sulfate polyacrylamide gel electrophoresis (SDS-PAGE) (Bio-Rad, Mini-PROTEAN® Tetra Handcast Systems, Portugal) based on the protocol of Laemmli [36]. The NOR used in these studies had a specific activity of $307 \mathrm{U} / \mathrm{mg}$, determined as described previously by Timóteo et al. [37], using an ISO-NO Mark II amperometric sensor (2 mm, World Precision Instruments, Inc., UK: one unit corresponds to $1 \mu \mathrm{mol}$ of $\mathrm{NO} / \mathrm{min}$ ).

\subsection{Lipidic structures}

Liposomes as lipidic bilayer were prepared by lipid film hydration method [38]. DOPE (zwitterionic phospholipids), DOTAP (cationic phospholipids) and DSPE-PEG (zwitterionic pegylated phospholipids) dispersed in chloroform were mixed at the volume ratio of 74.5:70:5.7. Then, the solvent was evaporated with nitrogen flow until getting a lipid film. The obtained dried film was dispersed in HEPES buffer and vortexed for $15 \mathrm{~min}$ in order to obtain multilamellar vesicles. The suspension was sonicated in an ultrasonic processor (Hielscher ultrasound technology UP400S; amplitude: 20\%; cycle: 1; time: $1 \mathrm{~min}$; pulse on: $10 \mathrm{~s}$; pulse off: $15 \mathrm{~s}$ ) in order to obtain unilamellar vesicles with low and homogenous size. The hydrodynamic size average measurements were performed by dynamic light scattering (DLS) (Malvern Zetasizer NANO ZS instrument). The zeta-potential was also assessed with the same equipment by the laser Doppler velocimetry technique. The liposomes with a concentration of $10 \mathrm{mM}$ exhibit a $D$-average of $228 \pm 10 \mathrm{~nm}$ and a zeta potential of $29.7 \pm 4 \mathrm{mV}$ evaluated at a 1:15 dilution (liposomes: HEPES buffer, v/v). After deposition in the electrode, the liposomes were dehydrated, forming a lipidic bilayer.

\subsection{Biosensor fabrication}

Firstly, the PGE (A=7.07 $\mathrm{mm}^{2}$; ALS Co., Ltd.; Tokyo, Japan) was successively treated by hand polished with 1.0 and $0.3 \mu \mathrm{m}$ alumina (Gravimeta Lda, Portugal), briefly sonicated with EtOH and finally rinsed with ultrapure water. The surface activation was performed by cyclic voltammetry $(\mathrm{CV})$ in $\mathrm{H}_{2} \mathrm{SO}_{4} 0.5 \mathrm{M}$ at $100 \mathrm{mV} / \mathrm{s}$ in the range of $0 \mathrm{~V}$ to $1.6 \mathrm{~V}$ (vs. $\mathrm{Ag} / \mathrm{AgCl} / \mathrm{Cl}^{-}$sat.). SWCNTs were prepared in $\mathrm{DMF}$ with a final concentration of $1.0 \mathrm{mg} / \mathrm{mL}$. $10.5 \mu \mathrm{L}$ of the nanocomposite [SWCNTs/(DOPE:DOTAP:DSPE-PEG)/NOR], prepared by mixing $4 \mu \mathrm{L}$ of SWCNTs suspension at $0.5 \mathrm{mg} / \mathrm{mL}$ (dilution of the SWCNTs stock suspension with phosphate buffer; $1: 1, v / v$ ) with $2.5 \mu \mathrm{L}$ of (DOPE:DOTAP:DSPE-PEG) at 74.5:70:5.7 volume ratio and $4 \mu \mathrm{L}$ of NOR at $307 \mathrm{U} / \mathrm{mg}$, were immobilized on the PGE surface using the solvent casting technique and left overnight at $4{ }^{\circ} \mathrm{C}$ (Scheme 1). When not in use, the biosensor was stored at $4{ }^{\circ} \mathrm{C}$ in $100 \mathrm{mM}$ of phosphate buffer with $0.02 \%$ DDM and $0.01 \%$ PE at pH 6.0. 
[SWCNTs/(DOPE:DOTAP:DSPE-PEG)/NOR] (4/2.5/4 (v/v/v))
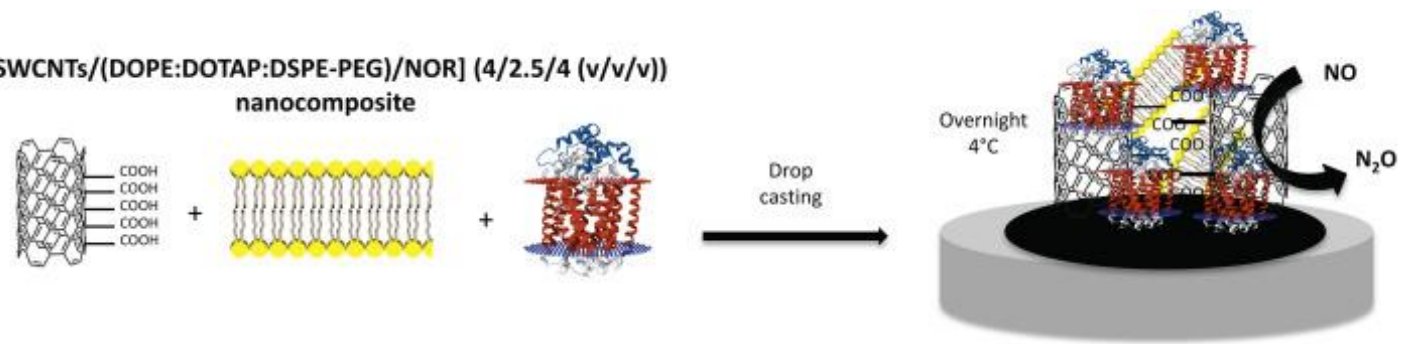

S

Pyrolytic graphite electrode

Lipidic bilayer (DOPE:DOTAP:DSPE-PEG) obtained as described in (I)

7. Marinobacter hydrocarbonoclasticus Nitric Oxide Reductase purified as described in (II)

(I)

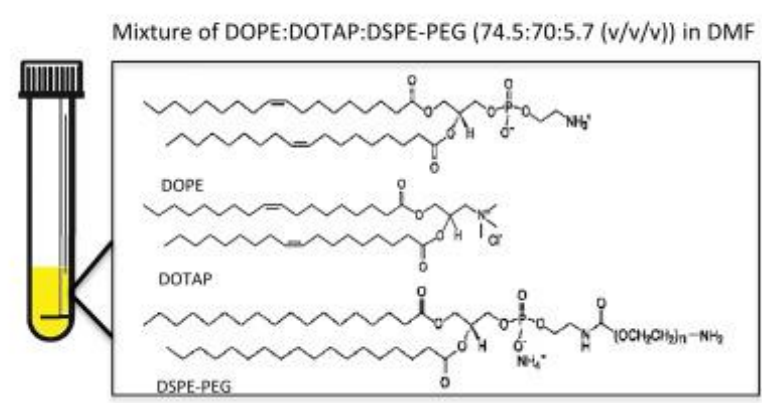

DSPEPEG

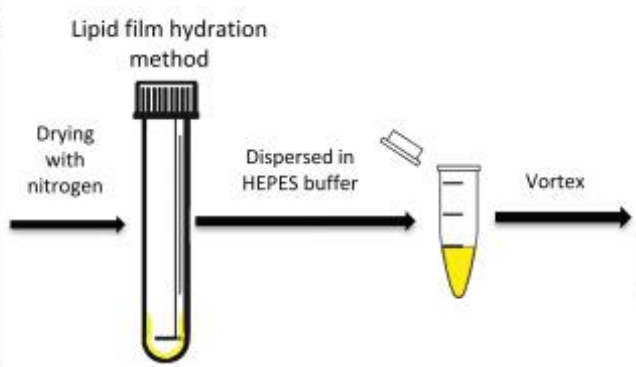

Dynamic Light Scattering characterization

(II)

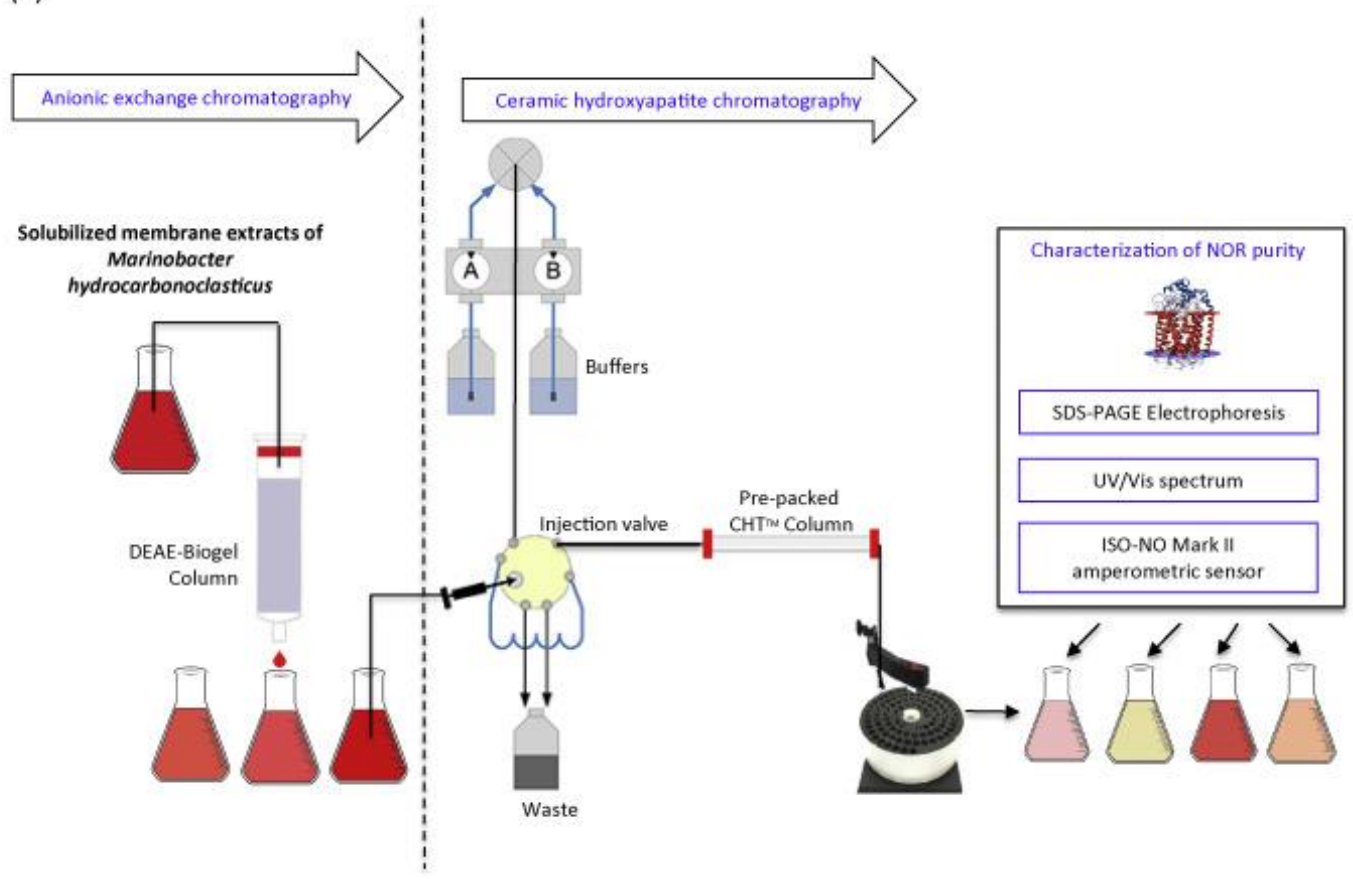

Scheme 1. Representation of the biosensor construction including the (I) lipidic structures preparation and (II) NOR purification. 


\subsection{Electrochemical measurements}

The modified PGE (PGE/SWCNTs; PGE/[SWCNTs/(DOPE:DOTAP:DSPE-PEG)] or PGE/[SWCNTs/(DOPE:DOTAP:DSPE-PEG)/NOR]) was set as the working electrode, and a platinum wire and silver/silver chloride saturated with $\mathrm{KCl} 3 \mathrm{M}$ were the secondary and reference electrodes, respectively. The three-electrode system was connected to an Autolab PGSTAT 204 potentiostat-galvanostat controlled by GPES 4.9.7 and Nova 1.10 software (Metrohm Autolab). The assays were conducted in one compartment cell using as electrolyte $100 \mathrm{mM}$ of phosphate buffer with $0.02 \% \mathrm{DDM}$ and $0.01 \% \mathrm{PE}$ at $\mathrm{pH} 6.0$ for NOR redox behavior and NO bioelectrocatalysis or the same buffer with $2.5 \mathrm{mM}$ $\left[\mathrm{Fe}(\mathrm{CN})_{6}\right]^{3-/ 4-}$ for characterization of the biosensor construction. The redox behavior of NOR was evaluated by square-wave voltammetry $(\mathrm{SWV})$ at the optimum parameters of $100 \mathrm{~Hz}$, amplitude of $20 \mathrm{mV}$ and step of $3 \mathrm{mV}$ in a potential scale range of +0.4 to $-1.0 \mathrm{~V}$ with a previous deoxygenation of the electrolyte using nitrogen gas during $20 \mathrm{~min}$. NO bioelectrocatalysis was performed in the same potential window and using the same SWV conditions with the exception of the frequency that was $10 \mathrm{~Hz}$. Electrochemical impedance spectroscopy (EIS) assays were performed in the buffer solution with $2.5 \mathrm{mM}$ $\left[\mathrm{Fe}(\mathrm{CN})_{6}\right]^{3-/ 4-}(\mathrm{pH} 6.0)$ applying a frequency range from $10^{-1}$ to $10^{5} \mathrm{~Hz}$ with an amplitude perturbation of $5 \mathrm{mV}$ and $0.2 \mathrm{~V}$ of conditioning potential.

\subsection{Morphological and structural characterization}

Scanning electron microscopy (SEM) with energy-dispersive X-ray spectroscopy (EDS) (High Resolution (Schottky) Environmental Scanning Electron Microscope with X-Ray Microanalysis and Electron Backscattered Diffraction analysis (Quanta 400 FEG ESEM/EDAX Genesis X4M)) was performed at the Centre of Materials of the University of Porto (Portugal). The Teflon parts of the electrodes were covered with an electrically conductive non-porous carbon tape (Agar Scientific; UK) appropriate for SEM analysis. The same energy of $25 \mathrm{keV}$, in the secondary electrons mode, was used for all samples.

Fourier transform infrared spectroscopy with attenuated total reflectance (FTIR-ATR) (Nicolet 6700 FTIR spectrometer (Thermo Scientific) controlled by OMNIC software) in the $400-4000 \mathrm{~cm}^{-1}$ range with a resolution of $4 \mathrm{~cm}^{-1}$ was also applied to characterize the biosensor construction. $1 \mu \mathrm{L}$ of each nanocomposite component or mixture used in the different stages of the biosensor development was used to carry out the FTIR-ATR assays.

\section{Results and discussion}

\subsection{Biosensor construction}

\subsubsection{Electrochemical characterization}

SWV and EIS assays performed using $\mathrm{Fe}(\mathrm{CN})_{6}{ }^{3-/ 4-}$ as electroactive indicator in the supporting electrolyte $(\mathrm{pH}=6.0)$ were used to characterize the different steps involved in the biosensor development. $\mathrm{pH}$ has a marked effect on NOR activity and it was maintained at the optimum value of 6.0 during all the experiments since, at this value, maximum enzyme catalytic activity was detected with the observed protonation of the residues surrounding the catalytic centre $[15,39] . \mathrm{pH}$ is a critical point on the development of enzymatic biosensors because it can promote changes in the shape of enzymes and in 
their Gibbs energy, as well in the ionic charge of the substrate [40]. Fig. 2-(A) displays the square-wave voltammograms obtained with the PGE, PGE/SWCNTs, PGE/[SWCNTs/(DOPE:DOTAP:DSPE-PEG)]

and

PGE/[SWCNTs/(DOPE:DOTAP:DSPE-PEG)/NOR]. As expected, the characteristic reduction peak of the electroactive indicator was detected at around $0.14-0.20 \mathrm{~V}$ by all the (bare and modified) electrodes. However, significantly different current intensities were attained in bare versus modified electrodes, showing the effect of the each performed modification. Drop casting of $2 \mu \mathrm{L}$ SWCNTs at $1 \mathrm{mg} / \mathrm{mL}$ onto the PGE surface promoted the biggest current increase (about 2.5 times). CNT-based biosensors generally have higher sensitivity and lower limit of detection due to the faster electron transfer kinetics, larger surface areas and electrocatalytic properties [7]. The amount of SWCNTs deposited on the surface of the PGE was optimized by testing three different volumes namely $1.0,2.0$, and $5.0 \mu \mathrm{L}$. Between 1 and $2 \mu \mathrm{L}$, the current peak increased almost proportionally with the SWCNTs quantity; between 2 and $5 \mu \mathrm{L}$, no significant current differences were observed. Hence, due to reproducibility issues using $5 \mu \mathrm{L}$, the optimum result was considered to be $2.0 \mu \mathrm{L}$ of $1.0 \mathrm{mg} / \mathrm{mL}$ SWCNTs or the equivalent amount (i.e. $4.0 \mu \mathrm{L}$ of $0.5 \mathrm{mg} / \mathrm{mL}$ SWCNTs when SWCNTs were mixed with DOPE:DOTAP:DSPEPEG and/or NOR). This quantity was also proved to be enough to cover the electrode surface and to promote a low standard deviation of the peak current.

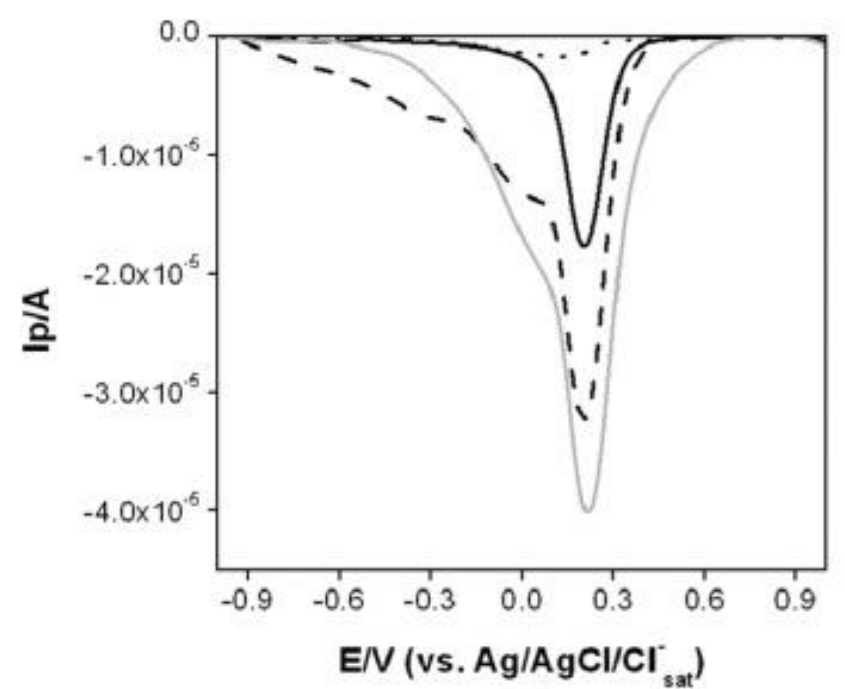

(A)

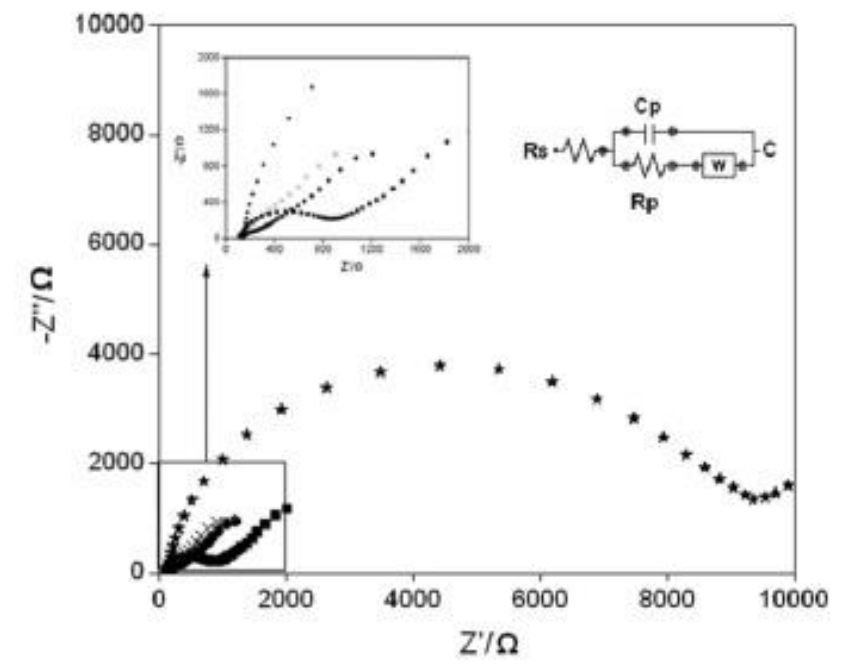

(B) 
Fig. 2. (A) Square-wave voltammograms of the different stages of the PGE biosensor development PGE ( ), PGE/SWCNTs , PGE/[SWCNTs/(DOPE:DOTAP:DSPE-PEG)] (____) and PGE/[SWCNTs/(DOPE:DOTAP:DSPE-PEG)/NOR] (.....) and (B) Nyquist plots (real impedance $Z^{\prime}$ vs. -imaginary impedance $Z^{\prime \prime}$ ) of PGE (匹), PGE/SWCNTs X, PGE/[SWCNTs/(DOPE:DOTAP:DSPE-PEG)] $(\bullet)$ and PGE/[SWCNTs/(DOPE:DOTAP:DSPE-PEG)/NOR] $\quad$ deoxygenated $2.5 \mathrm{mM}\left[\mathrm{Fe}(\mathrm{CN})_{6}\right]^{3-/ 4-}$ and $100 \mathrm{mM}$ of phosphate buffer with $0.02 \% \mathrm{n}$-dodecyl- $\beta$-D-maltoside and $0.01 \% 2-$ phenylethanol (pH 6.0). Square-wave voltammetry parameters: frequency of $50 \mathrm{~Hz}$, amplitude of $50 \mathrm{mV}$ and step potential of $2 \mathrm{mV}$; electrochemical impedance spectroscopy conditions: frequency range from $10^{-1}$ to $10^{5} \mathrm{~Hz}$ with an amplitude perturbation of $5 \mathrm{mV}$ and $0.2 \mathrm{~V}$ of conditioning potential. (C) Equivalent electrical circuit composed by the resistance of the solution (Rs/ $\Omega$ ), the Warburg impedance $(\mathrm{W} / \Omega)$, the double-layer capacitance $(\mathrm{Cp} / \mathrm{F})$, and the electron transfer resistance $(\mathrm{Rp} / \Omega)$.

To mimic the NOR cellular environment and to increase the enzyme stability and lifetime, the SWCNTs were mixed with the selected lipidic suspension (DOPE:DOTAP:DSPEPEG; 74.5:70:5.7 volume ratio) [31]. The composition of the lipidic bilayer had high amount of DOPE phospholipids in order to simulate biological membranes. However, to increase its stability on the electrode surface, positive charged phospholipids (DOTAP) were also included. In this way, the lipidic bilayer interacted electrostatically with the negative charged (due to functionalization with carboxylic groups) SWCNTs. The lipidic bilayer concentration effect on the PGE/[SWCNTs/(DOPE:DOTAP:DSPE-PEG)] signal was evaluated by comparison with the current intensity reached with PGE/SWCNTs. $2.5 \mu \mathrm{L}$ of the lipidic bilayer mixture at five different concentrations of $(1: 5000,1: 500$, 1:250, 1:25 and 1:15 liposomes:HEPES buffer ratio; $v / v)$ were tested (Fig. 3). The ratios of 1:5000, 1:500 and 1:250 (with not detectable, 6.0 and 13.9\% peak reduction, respectively) did not promote a significant impact on the peak current of the PGE/[SWCNTs/(DOPE:DOTAP:DSPE-PEG)] suggesting insufficient amount of lipidic bilayer; the successful incorporation of phospholipids in a biosensor platform is expected to promote a significant diminution of the current peak caused by the negative effect on electron transfer reaction [41]. When the ratio was increased to 1:25 and 1:15 (v/v), the peak current markedly decreased (21.9-34.1\%) showing that the lipidic bilayer significantly interacted with the SWCNTs. These results can be due to the presence of higher amount of lipidic bilayer and by the electrostatic interactions between the positive charges of the lipidic bilayer (zeta potential of $29.7 \mathrm{mV}$ ) and the negative charges of the carboxilated groups of the SWCNTs. When the lipidic bilayer was highly diluted (1:250 to $1: 5000, \mathrm{v} / \mathrm{v}$ ), the zeta potential decreased and became less positive hampering the interactions. Therefore, the 1:15 ( $v / v)$ (DOPE:DOTAP:DSPE-PEG):HEPES buffer ratio (corresponding to $0.67 \mathrm{mM}$ of DOPE:DOTAP:DSPE-PEG) was considered the optimum concentration to prepare the nanocomposite since appropriate peak current reduction was perceived. These results are not comparable with literature data since no similar study was found regarding enzymatic biosensors development. The integration of NOR in the prepared nanocomposite [SWCNTs/(DOPE:DOTAP:DSPE-PEG)/NOR] (4/2.5/4, $\mathrm{v} / \mathrm{v} / \mathrm{v})$ ), used to modify the PGE, caused a significant deviation of the electroactive indicator peak potential $(0.137 \pm 0.009 \mathrm{~V}$ instead of the initial potential of $0.200 \pm 0.009 \mathrm{~V}$ ) and a significant decrease of the current (23 and 29 times lower when compared with the PGE/[SWCNTs/(DOPE:DOTAP:DSPE-PEG)] and PGE/SWCNTs, respectively). This behavior suggested that NOR was successful entrapped, which can electrostatically interact through the protonated amino groups and/or deprotonated carboxylic groups of its different aminoacids (working $\mathrm{pH}=6.0$; e.g. methionine, histidine and glycine, as well as one non-essential aminoacid, glutamic acid, surround NOR centers [42]) with the negatively charged SWCNTs and with the positively charged lipidic bilayer; steric interactions could also occur. No significant differences were detected when $7 \mu \mathrm{L}$ were tested instead of $4 \mu \mathrm{L}$ of NOR. 


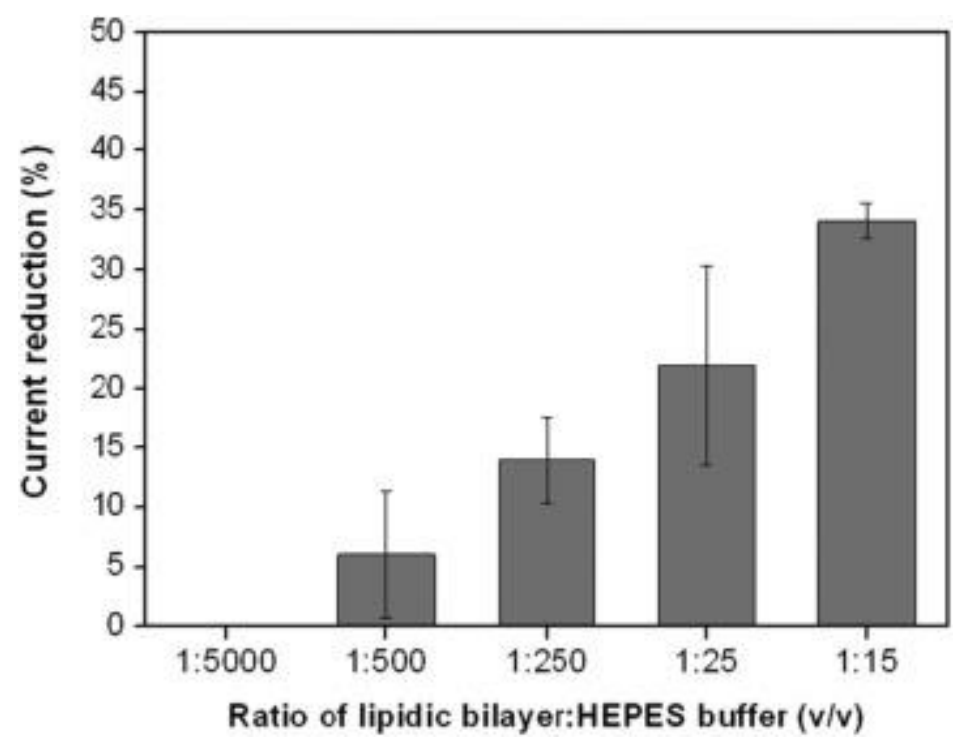

Fig. 3. Peak current reduction (\%) of the PGE/[SWCNTs/(DOPE:DOTAP:DSPE-PEG)] (when compared with PGE/SWCNTs) versus ratio of lipidic bilayer (DOPE:DOTAP:DSPE-PEG; 74.5:70:5.7 (v/v/v)):HEPES buffer $(v / v)$. Experimental square-wave voltammetry conditions: frequency of $50 \mathrm{~Hz}$, amplitude of $50 \mathrm{mV}$ and step potential of $2 \mathrm{mV}, 2.5 \mathrm{mM}\left[\mathrm{Fe}(\mathrm{CN})_{6}\right]^{3-/ 4-}$ in deoxygenated $100 \mathrm{mM}$ of phosphate buffer with $0.02 \%$ n-dodecyl- $\beta$-D-maltoside and $0.01 \%$ 2-phenylethanol ( $\mathrm{pH} 6.0$ ).

EIS assays (Fig. 2-(B)-(C); Fig. SM2; Table SM1, Supplementary Material) were also performed to supplement SWV data. A Randles equivalent circuit of $\mathrm{Rs}(\mathrm{Cp}[\mathrm{RpW}])$ (it includes the polarization resistance $(\mathrm{Rp} / \Omega)$, the resistance of the solution $(\mathrm{Rs} / \Omega)$, the

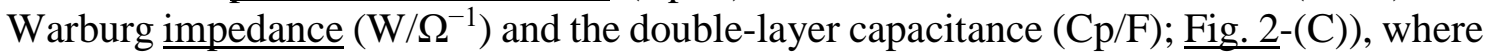
polarization is due to a combination of kinetic and diffusion models $[43,44]$, was used to model the impedance spectra and to calculate the impedance parameters (Fig. SM2; Table SM1, Supplementary Material). In this technique, changes in electron transfer resistance can be determined by the diameter of the semicircle observed at high frequencies (Fig. 2(B); Fig. SM2, Supplementary Material). Therefore, EIS measurements were employed to characterize the electron transfer efficiency of the proposed biosensor. Significant differences between the attained Rp of the PGE, PGE/SWCNTs, PGE/[SWCNTs/(DOPE:DOTAP:DSPE-PEG)] and PGE/[SWCNTs/(DOPE:DOTAP:DSPE-PEG)/NOR] can be observed (Fig. 2-(B)). The redox process at PGE displayed low resistance with a value of $653 \Omega$. When the SWCNTs were casted on the PGE surface, no semicircle was observed indicating that the interfacial electron transfer was improved due to the inherent SWCNTs properties. With the incorporation of the lipid bilayer, and subsequently NOR, the Rp considerably increased reaching $7.70 \mathrm{k} \Omega$, which explain the decreased peak currents noticed in SWV. Therefore, these results further reinforce that the immobilization of NOR in the prepared nanocomposite was effectively accomplished. Moreover, the time needed for the stabilization of the PGE/[SWCNTs/(DOPE:DOTAP:DSPE-PEG)/NOR] signal was assessed during ten consecutive days, using five freshly prepared biosensors. From day zero to day one, a 35\% current augmentation was perceived, while no further meaningful changes were noted during the remainder tested period $\left(-2.49 \times 10^{-6} \pm 3.71 \times 10^{-7} \mathrm{~A}\right.$ (day 0 ); $-3.37 \times 10^{-6} \pm 3.32 \times 10^{-7}$ A (day 1) to $-3.57 \times 10^{-6} \pm 3.59 \times 10^{-7} \mathrm{~A}($ day 10$) ; n=5$ ). One day was, thus, sufficient to obtain the NOR perfect rearrangement/conformation within the proposed biosensor. Compared to the free forms, immobilizing enzymes in nano- or bio-materials, including lipidic bilayer, can confer longer stability, improvement in selectivity and activity, and easier manipulation $[\underline{45}, \underline{46}]$. This time period (one day) 
was chosen as the operational stabilization time before the electroanalytical application of the proposed biosensor.

\subsubsection{Morphological and structural characterization}

Fig. 4 illustrates the surface morphology of the biosensor at the different stages of construction. The PGE/SWCNTs surface shows a common morphology [47] with carbon nanotube filaments well-distributed and forming an homogeneous film without damage (Fig. 4 (A)). When the lipidic bilayer was mixed with the SWCNTs (Fig. 4 (B)), some prominences, protuberances and shadows were perceived originating a consistent film structure, which may still be considered homogeneous. It has been proposed that, after the SWCNTs incorporation in lipids or other amphiphilic surfactants, the tubes could be adsorbed by the surfactants in a randomly distributed form or created the core of cylindrical micelles [48]. The introduction of NOR in the nanocomposite resulted in a completely different surface morphology, significantly less flat, more irregular, with a film similar to a gel (Fig. 4 (C) compared with Fig. 4 (B)), thus, demonstrating the well distribution of NOR (this enzyme is obtained after purification in buffer solution as a gel) in the prepared nanocomposite. A similar effect was obtained by Guan et al. [25] using lipids and another enzyme (tyrosinase). The presence of DDM (the detergent used in enzyme purification) in the nanocomposite is very low $(0.0076 \%)$, and, although, some detergents may induce morphological changes of the lipidic structures, no significant changes were detected. 


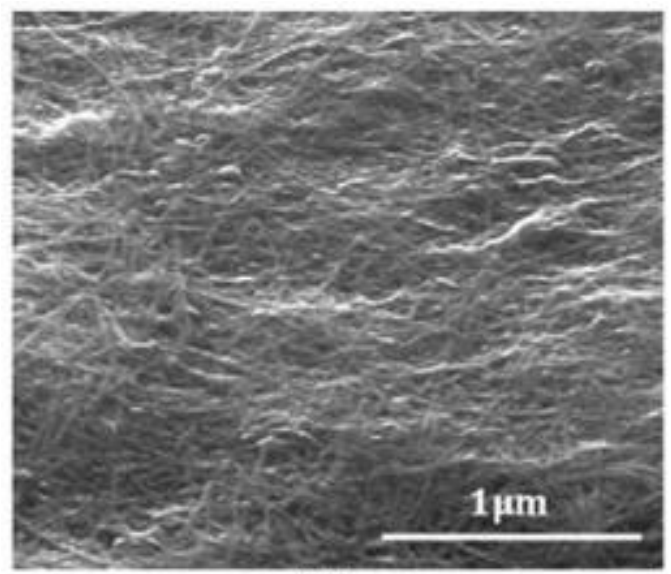

(A)

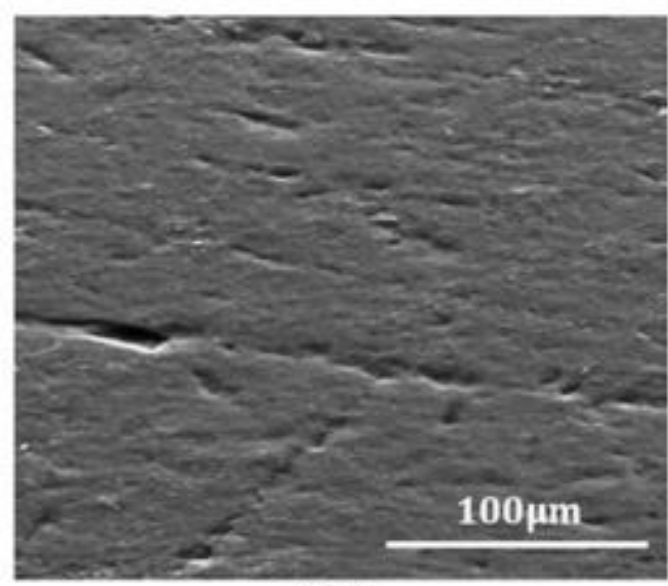

(B)-1

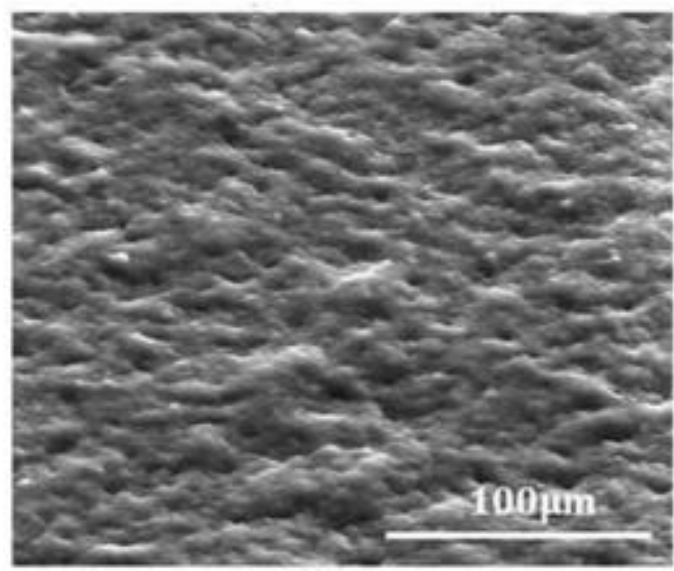

(C)-1

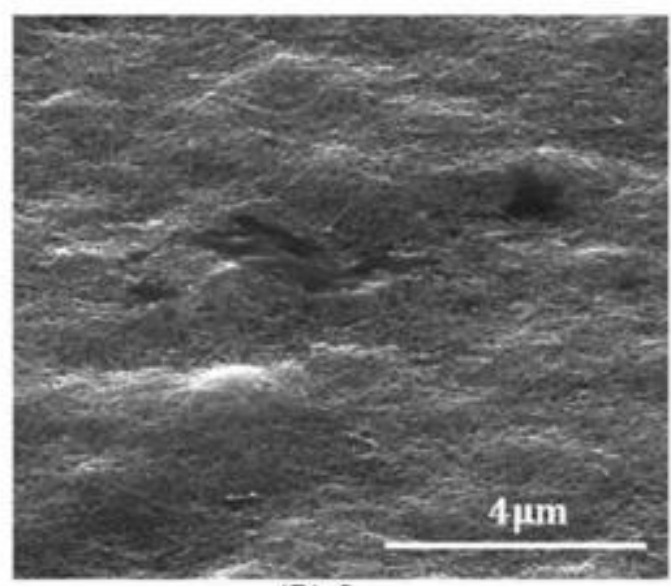

(B)-2

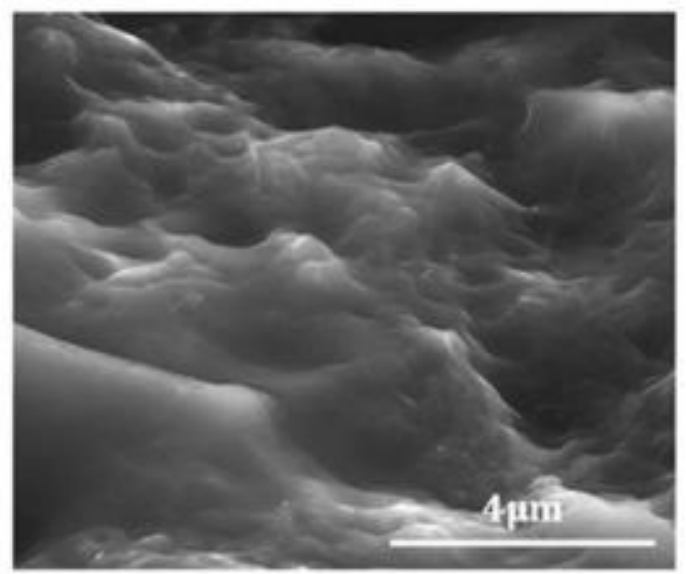

(C)-2

Fig. 4. Scanning electron microscopy images of (A) PGE/SWCNTs, (B) PGE/[SWCNTs/(DOPE:DOTAP:DSPE-PEG) and (C) PGE/[SWCNTs(DOPE:DOTAP:DSPE-PEG)/NOR].

Regarding the results of FTIR spectroscopy (Fig. 5), the spectrum of NOR (Fig. 5 (A)) displayed the typical vibration of the amide bond of proteins (amide I at $1545 \mathrm{~cm}^{-1}$ and amide II at $1654 \mathrm{~cm}^{-1}$ ) [49, $\underline{50]}$. Other stretching vibrations, such as $\mathrm{C}-\mathrm{N}$ at 1029,1074 and $1149 \mathrm{~cm}^{-1}$, and $\mathrm{C}-\mathrm{H}$ at 2854 and $2922 \mathrm{~cm}^{-1}$ were also observed $[49,50]$. The strongest SWCNTs band (Fig. 5 (B)) appeared at ca. $1650 \mathrm{~cm}^{-1}$ and can be attributed to $\mathrm{COOH}$ stretching, confirming the carbon nanotubes functionalization with carboxylic 
groups [ [51, 52]. Other bands, with wavenumber of 1064, 1103, 1253, 1388, 1436, 1498, and $3023-3646 \mathrm{~cm}^{1}$, arose from the solvent used to prepare the SWCNTs suspension (DMF) [53]. The spectra of [SWCNTs/(DOPE:DOTAP:DSPE-PEG)] and [SWCNTs/(DOPE:DOTAP:DSPE-PEG)/NOR] were similar with the SWCNTs one; the main difference is related with the $\mathrm{COOH}$ band transmittance values $(70,59$ and 33 a.u. for SWCNTs, SWCNTs/(DOPE:DOTAP:DSPE-PEG) and SWCNTs/(DOPE:DOTAP:DSPE-PEG)/NOR, respectively). Clearly, the stability of the film and consequent enhanced performance of the proposed biosensor resulted from the steric interactions, hydrogen-bond interactions among the carboxylic acid groups of SWCNTs, the protonated imine nitrogen atom of the lipidic bilayer and the amino and carboxylic groups of the NOR amino acid residues.

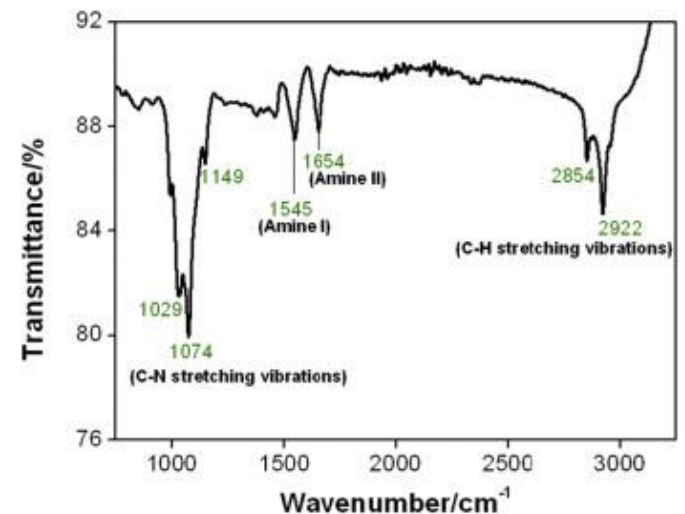

(A)

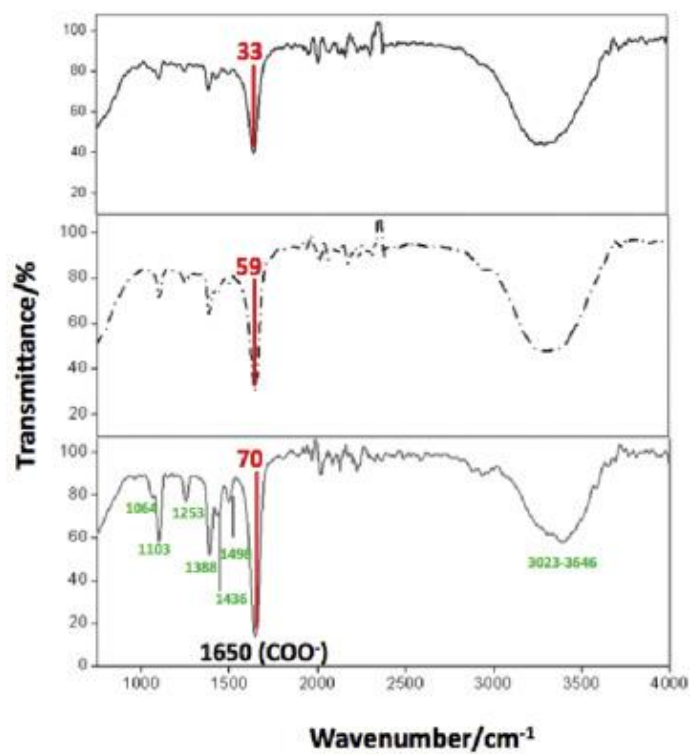

(B)

Fig. 5. Fourier transform infrared spectroscopy with attenuated total reflectance spectra of (A) NOR enzyme and (B) of the different stages (SWCNTs ; SWCNTs/(DOPE:DOTAP:DSPE-PEG) (_._-_) and SWCNTs/(DOPE:DOTAP:DSPE-PEG)/NOR of the biosensor development.

\subsection{Direct electron transfer behavior of nitric oxide reductase}

Comparative square-wave voltammograms of the direct electrochemical response of NOR on PGE and on the proposed biosensor are shown in Fig. 6 (assays performed without an electroactive indicator i.e. in $100 \mathrm{mM}$ of phosphate buffer with $0.02 \%$ DDM 
and $0.01 \% \mathrm{PE} \mathrm{(pH} \mathrm{6.0)).} \mathrm{To} \mathrm{attain} \mathrm{the} \mathrm{best} \mathrm{electroanalytical} \mathrm{signal,} \mathrm{the} \mathrm{parameters} \mathrm{of}$ $\mathrm{SW} V$ were optimized. Briefly, the frequency was ranged from 10 to $285 \mathrm{~Hz}$, the amplitude from 5 to $50 \mathrm{mV}$ and the step from 1 to $4 \mathrm{mV}$. Considering the peak baseline, definition and current, the most adequate $\mathrm{SW} V$ parameters for subsequent NOR direct electron transfer (DET) characterization were a frequency of $100 \mathrm{~Hz}$, a pulse amplitude of $20 \mathrm{mV}$ and a step potential of $3 \mathrm{mV}$. The high sensitivity of SWV allowed to perceive two centers of the enzyme on PGE/NOR: peak 1, at $-0.406 \pm 0.002 \mathrm{~V}$, was attributed to the heme $b_{3}$, and peak 2, at $-0.272 \pm 0.004 \mathrm{~V}$, to heme $b$. The other NOR centers (heme $c$ and nonheme $\mathrm{Fe}_{\mathrm{B}}$ at ca. $0.05 \mathrm{~V}$ and $-0.58 \mathrm{~V}$, respectively) were not detected under the applied experimental conditions; the observation of only some of its metallic centers is common in electrochemical studies of NOR [14] but also of other enzymes [44] due to different conformation and orientation at the electrode surface. On PGE/[SWCNTs/(DOPE:DOTAP:DSPE-PEG)/NOR], only the peak corresponding to the low spin heme $b_{3}$ bi-nuclear catalytic center was distinctly observed, at a lesser negative potential, $-0.308 \pm 0.003 \mathrm{~V}$. This heme, part of the active site, is the one more easily detected probably by electrochemistry, probably because it is usually more exposed and more adequately orientated to the electrode surface [14]. Cordas et al. $[13,14]$ have been involved in the characterization of NOR subunits and catalytic mechanism including the identification of the potential of its four centers. The results attained in this study are in agreement with those previously reported by these authors [13] with non-significant deviations in the heme potentials. Moreover, an enhanced sensitivity was noticed with the reduction current of heme-( $\mathrm{Fe}(\mathrm{III}) / \mathrm{Fe}$ (II) eight times higher on the developed biosensor than on PGE/NOR. This favorable behavior is directly linked with the adopted immobilization strategy and with the fast electron-transfer rates between heme $c$ /heme $b$, and heme $b /$ heme $b_{3}$ in the bi-nuclear site [15]. Using different square-wave frequencies $(10$ to $285 \mathrm{~Hz} ; n=8)$, the surface concentration of the electroactive species $\left(\tau * / \mathrm{mol} \mathrm{cm}^{-2}\right)$ was estimated for PGE/[SWCNTs/(DOPE:DOTAP:DSPE-PEG)/NOR] biosensor. The evaluation was done using the Faradic Eq. [54] and considering the geometric area of the electrode, since the real area of the modified electrode cannot be determined due to unidentified diffusion coefficient. The electroactive species surface concentration on the PGE/[SWCNTs/(DOPE:DOTAP:DSPE-PEG)/NOR] biosensor, $1.10 \times 10^{-10} \mathrm{~mol} \mathrm{~cm}^{-2}$, is ca 7 times higher than the one reported by Cordas et al. [14] for NOR immobilized onto a PGE $\left(1.52 \times 10^{-11} \mathrm{~mol} \mathrm{~cm}^{-2}\right)$. This improved result is due to the large specific surface area of SWCNTs and DOPE:DOTAP:DSPE-PEG, that allowed the existence of additional sites with active NOR. Furthermore, the determined surface coverage is comparable with other data from previous reported biosensors, namely those based on DET of hemoglobin adsorbed on the gold colloids modified carbon paste electrode or captured in a cationic gemini surfactant film [55]. 


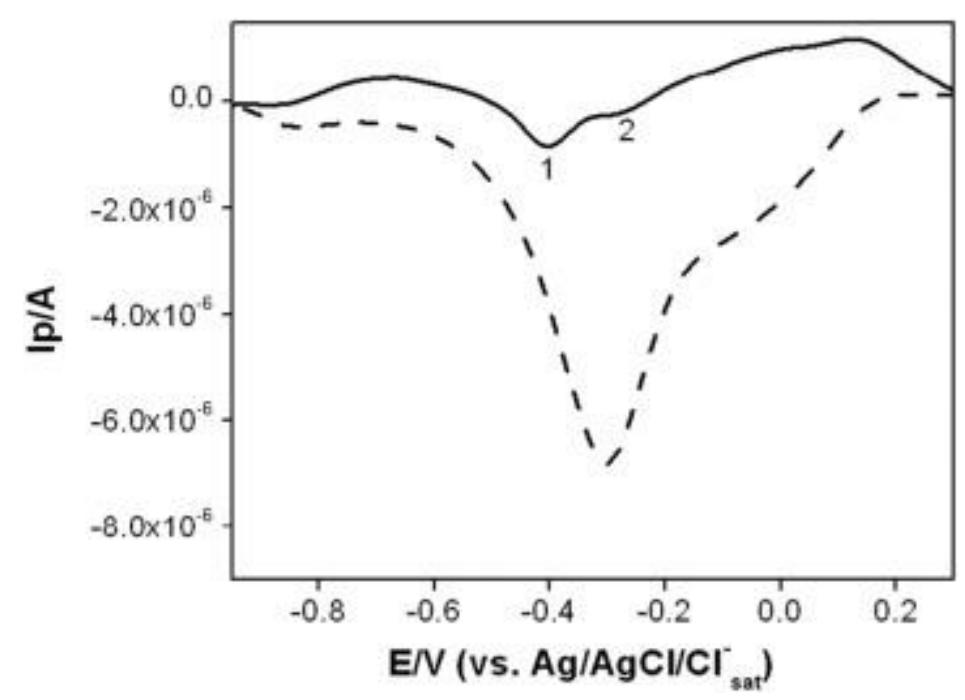

Fig. 6. Comparative square wave voltammograms of direct electrochemical behavior of NOR on PGE (___ and PGE/[SWCNTs/(DOPE:DOTAP:DSPE-PEG)/NOR] (____ ). Peaks 1 and 2 correspond to heme $b_{3}$ and heme $b$ centers, respectively. Experimental conditions: frequency of $100 \mathrm{~Hz}$, amplitude of $20 \mathrm{mV}$ and step potential of $3 \mathrm{mV}$ in deoxygenated $100 \mathrm{mM}$ of phosphate buffer with $0.02 \%$ n-dodecyl- $\beta$-D-maltoside and $0.01 \%$ 2-phenylethanol (pH 6.0).

The influence of surface PGE modification in kinetics performance was also evaluated using the apparent electron transfer rate constant $\left(\mathrm{K}_{\mathrm{app}}\right)$ estimated by eq. (1) [6ㅜ:(1)

where $\mathrm{R}$ is the ideal gas constant $\left(\mathrm{J} \mathrm{mol}^{-1} \mathrm{~K}^{-1}\right), \mathrm{T}$ is the temperature $(\mathrm{K}), \mathrm{n}$ is the number of electrons involved in reaction $(n=1), \mathrm{F}$ is the Faraday constant $\left(\mathrm{C} \mathrm{mol}^{-1}\right), \mathrm{A}$ is the electrode area $\left(\mathrm{cm}^{2}\right), \mathrm{Rp}$ is the charge transfer resistance $(\Omega)$ and $\mathrm{C}$ is the concentration of the redox species $\left(\mathrm{mol} \mathrm{cm}{ }^{-3}\right)$. A value of $1.96 \times 10^{-4} \mathrm{~cm} \mathrm{~s}^{-1}$ was reached for the PGE/[SWCNTs/(DOPE:DOTAP:DSPE-PEG)/NOR] biosensor, which unequivocally demonstrates its fast electron transfer process, being comparable with values reported for other enzymatic biosensors [57].

\subsection{Direct bioelectrocatalytic analysis of nitric oxide}

Since NO is reduced by the selected bacterial NOR enzyme with the formation of nitrous oxide and water (eq. (2)), the response of the proposed biosensor to NO was studied. Clear distinct profiles were observed (Fig SM3, Supplementary Material; Fig. 7). The NO reduction catalytic potential (defined as the midpoint potential of the observed electrocatalytic wave [58]; Fig. SM4, Supplementary Material) was evidenced at $-0.69 \pm 0.02 \mathrm{~V}$, a value similar to the one reported for other heme-protein (hemoglobin and myoglobin) sensors [[59], [60], [61]]. NOR can also catalyze the reduction of dioxygen, because it has similarities with the heme copper oxidases family, namely a similar catalytic center [62]. However, as previously described, the reduction of NO and dioxygen occur at a distinct potential (ca. $-0.70 \mathrm{~V}$ for $\mathrm{NO}$ and ca. $-0.25 \mathrm{~V}$ for $\mathrm{O}_{2}$; Fig. SM5; Supplementary Material) and with NOR exhibiting significantly higher affinity for its natural substrate (NO) [63]. Moreover, in this study, all assays were performed in anaerobic conditions. The optimum SWV parameters for NO bioelectrocatalysis were determined as being $10 \mathrm{~Hz}, 20 \mathrm{mV}$ and $3 \mathrm{mV}$ for the frequency, pulse amplitude and the staircase step, respectively.(2) 


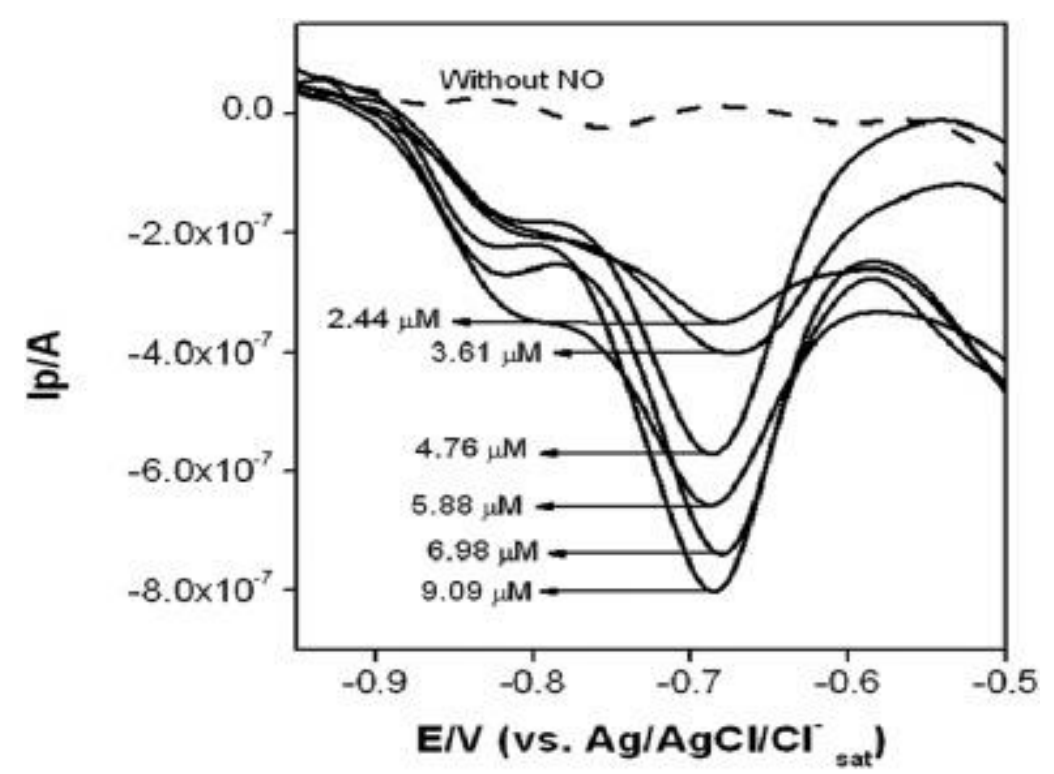

(A)

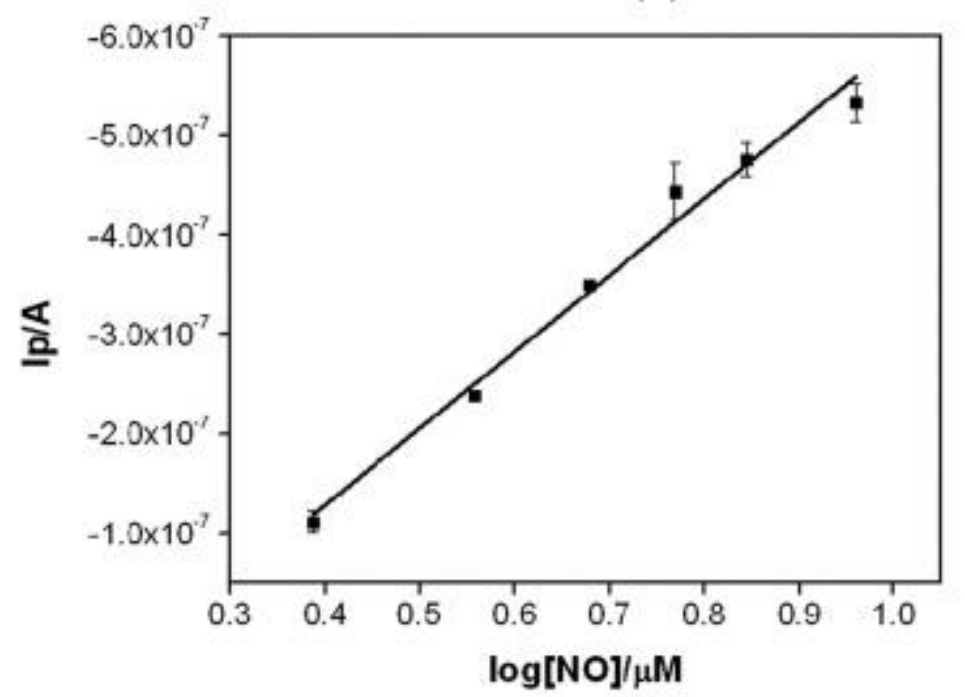

(B)

Fig. 7. Square wave voltammograms obtained with PGE/[SWCNTs/(DOPE:DOTAP:DSPE-PEG)/NOR] in the absence of NO and in the presence of standard NO concentrations of 2.44, 3.61, 4.76, 5.88, 6.98 and $9.09 \mu \mathrm{M}$ (A); respective calibration curve (B). Experimental conditions: frequency of $10 \mathrm{~Hz}$, amplitude of $20 \mathrm{mV}$ and step potential of $3 \mathrm{mV}$ in deoxygenated $100 \mathrm{mM}$ of phosphate buffer with $0.02 \% \mathrm{n}$-dodecyl- $\beta$-D-maltoside and $0.01 \%$ 2-phenylethanol ( $\mathrm{pH} 6.0$ ).

The majority of studies reported in the literature regarding the interaction of NO with different types of NOR are theoretical studies [[64], [65], [66]]; only a few works are based on electrochemical techniques [[13], [14], [15], [16], [17]]. Several possible mechanisms for the bioelectrocatalytic NO reduction by NOR have been described based on experimental and computational data, namely the trans-mechanism, the cis- $\mathrm{Fe}_{\mathrm{B}}$ and the cis-heme $b_{3}$ mechanism [67]. However, due to the very limited information regarding this enzyme, the real mechanism is not yet established and is a still a matter of debate $[\underline{13}, \underline{15}, \underline{66}]$. The Michaelis-Menten constant $\left(K_{\mathrm{m}} / \mathrm{M}\right)$, that indicates the biological activity including the kinetic constants of immobilized enzymes, was determined using the Michaelis-Menten eq. (3) [68]:(3)

where $I_{s s}(\mathrm{~A})$ is the steady-state current after addition of the substrate; $C(\mathrm{M})$ is the concentration of the substrate and $I_{\max }(\mathrm{A})$ is the maximum current measured [68]. The 
estimated $K_{\mathrm{m}}$ of $4.3 \mu \mathrm{M}$ (Fig. SM6, Supplementary Material) shows that the high NOR activity was well preserved after its immobilization on the biosensor. This low micromolar $K_{\mathrm{m}}$ value also highlights the clear benefits of using an enzyme specific for NO (NOR) on the biosensor. With a couple of exceptions $[\underline{71}, \underline{72}]$, most of the NO thirdgeneration biosensors (based on heme proteins and porphyrins $[\underline{61}, \underline{69}, \underline{70}]$ ) display considerably higher $K_{\mathrm{m}}$ values.

Fig. 7 displays the biosensor response to different standard NO concentrations under the optimized conditions (the blank is also included; frequency of $10 \mathrm{~Hz}$, amplitude of $20 \mathrm{mV}$ and step potential of $3 \mathrm{mV}$ in $100 \mathrm{mM}$ of phosphate buffer with $0.02 \% \mathrm{DDM}$ and $0.01 \%$ $\mathrm{PE}\left(\mathrm{pH}\right.$ 6.0)). The obtained calibration curve $\left(\mathrm{I}(\mathrm{A})=-7.70 \times 10^{-7} \pm 4.65 \times 10^{-8} \log [\mathrm{NO}]\right.$ $(\mu \mathrm{M})+1.80 \times 10^{-7} \pm 3.37 \times 10^{-8}, \quad n=6 ; \quad \underline{\text { Fig. } 7}$ (B)) presented good sensitivity $(0.77 \mu \mathrm{A} / \log \mu \mathrm{M})$, satisfactory linear range $(0.44$ to $9.09 \mu \mathrm{M} N O)$, data with low standard deviation $(0.4$ to $9.5 \%)$ and acceptable quadratic correlation coefficient $\left(r^{2}=0.986\right)$. Values of $0.13 \mu \mathrm{M}$ for limit of detection (LOD) and $0.44 \mu \mathrm{M}$ for limit of quantification (LOQ) were estimated based on $3 *$ Sy-intercept/slope and $10 *$ Sy-intercept/slope, respectively, where Sy-intercept is the standard deviation of the y-intercept [73]. The main figures of merit compare favorably with those described for hemoglobin- [70,74] and cyt $c$-based NO sensors $[\underline{61}, \underline{69}, \underline{75}]$, as well as, for enzymatic biosensors based on lipidic bilayer (Table 1); the only two exceptions were one Tyr- and one acetylcholinesterase-based biosensor for phenolic compounds [25] and organophosphate pesticides (dichlorvos used as a model compound), respectively [29]. The proposed PGE/[SWCNTs/(DOPE:DOTAP:DSPE-PEG)/NOR] biosensor may be applicable to screen NO levels released from biological systems. Previous scarce in vivo studies have been reporting NO concentrations in the order of 1 to $3 \mu \mathrm{M}$ in rat liver and brain $[\underline{55}, \underline{70},[76],[77],[78]]$.

The intra-day repeatability and the reproducibility of the device were estimated by carrying out five analyses in the same day and by independently preparing and testing five biosensors, respectively. The values of relative standard deviation ranged from 4.1 to $7.0 \%$ for the NO concentration level of $4.76 \mu \mathrm{M}$. In addition, the long-term stability and the continuous activity of the built biosensor were examined during five weeks. The results showed that the biosensor retained approximately $97 \%$ of the initial response after one week and $83.5 \%$ after five weeks, clearly demostrating that the selected NOR immobilization approach maintains the bioelectrocatalytic activity for a long period of time. These data also suggested that drop casting of the nanocomposite on PGE provided sufficient binding to the electrode surface and between the three components, with no significant leaching during the tested period. Furthermore, the attained data compare favorably $[\underline{25}, \underline{26}]$ or are in agreement $[\underline{28}, \underline{29}]$ with those from other architected enzymatic biosensors based on lipidic bilayer (Table 1).

Due to the fast diffusion $\left(\mathrm{k} \approx 10^{10}-10^{11} \mathrm{~mol}^{-1} \mathrm{Ls}^{-1}\right)$ of NO and its significant reactivity with $\mathrm{O}_{2}\left(k \approx 10^{6}-10^{7} \mathrm{~mol}^{-1} \mathrm{Ls}^{-1}\right)$, and other radicals, it has a very short half-life (in the order of the few seconds [5]), which greatly hampers the application of different techniques to the same sample for analytical data comparison. Thus, recovery assays were used to assess the selectivity of the PGE/[SWCNTs/(DOPE:DOTAP:DSPE-PEG)/NOR] by testing the presence of compounds that potentially co-exist with $\mathrm{NO}$ (or are promoters of NO production) in biological systems. L-arginine (L-Arg), ascorbic acid (AA), sodium nitrate $\left(\mathrm{NO}_{3}{ }^{-}\right)$, sodium nitrite $\left(\mathrm{NO}_{2}^{-}\right)$and glucose are the most common species that may cause interference during the electrochemical detection of NO [72] and, thus, their 
individual effect on the $\mathrm{NO}$ peak current was tested at $200 \mu \mathrm{M}$ for $\mathrm{L}-\mathrm{Arg}, \mathrm{NO}_{3}{ }^{-}$and $\mathrm{NO}_{2}{ }^{-}$, $20 \mu \mathrm{M}$ for AA and $800 \mu \mathrm{M}$ for glucose, while the NO concentration was $4.76 \mu \mathrm{M}$. The biosensor demonstrated excellent performance with recovery values of $98.4 \pm 5.3 \%$, $97.3 \pm 2.3 \%, 91.0 \pm 9.3 \%, 91.3 \pm 3.0 \%$ and $98.0 \pm 8.8 \%$ for L-Arg, $\mathrm{AA}, \mathrm{NO}_{3}{ }^{-}, \mathrm{NO}_{2}{ }^{-}$and glucose, respectively.

\section{Conclusions}

A biomimetic nanocomposite prepared with carboxylated SWCNTs, lipidic bilayer (DOPE:DOTAP:DSPE-PEG) and NOR was optimized and used to modify a PGE to construct a new third generation enzymatic biosensor. The proposed PGE/[SWCNTs/(DOPE:DOTAP:DSPE-PEG)/NOR] exhibited excellent structural stability and selectivity, combined with good bioelectrocatalytic activity and sensitivity towards NO detection. Still, some challenges remained unaddressed and are going to be explored in the near future. Further improvements may be achieved by the replacement of pyrolytic graphite electrodes by microelectrodes. The combination of the inherent advantages of microelectrodes with the high specificity of NOR can lead to interesting progresses towards monitoring the spatial and temporal profiles of NO formation and consumption in real biological systems.

\section{Acknowledgments}

FG thanks to Fundacão para a Ciência e a Tecnologia, MCTES (FCT/MCTES) for the fellowship grant SFRH/BD/52502/2014, which is financed by national funds and cofinanced by FSE. LBM thanks to FCT/MCTES for the CEEC-Individual 2017 Program Contract. This work was supported by the PTDC/BB-BQB/0129/2014 project (FCT/MCTES), by FCT/MEC with national funds and co-funded by FEDER, and also by the Associate Laboratory Research Unit for Green Chemistry - Technologies and Processes Clean - LAQV, financed by national funds from FCT/MCTES (UID/QUI/50006/2019). The financial support from the European Union (FEDER funds through COMPETE) and National Funds (Fundação para a Ciência e Tecnologia-FCT) through project PTDC/ASP-PES/29547/2017, by FCT/MEC with national funds and cofunded by FEDER, is also acknowledged. J.A. Loureiro post-doc grant was supported by NORTE-01-0145-FEDER-000005 - LEPABE-2 ECO-INNOVATION, from North Portugal Regional Operational Program (NORTE 2020), under the Portugal 2020 Partnership Agreement, through the European Regional Development Fund (ERDF).

\section{References}

[1]

P. Tavares, A.S. Pereira, J.J.G. Moura, I. MouraMetalloenzymes of the denitrification pathway

J. Inorg. Biochem., 100 (2006), pp. 2087-2100

J. Hendriks, A. Oubrie, J. Castresana, A. Urbani, S. Gemeinhardt, M. SarasteNitric oxide reductases in bacteria 
Biochim. Biophys. Acta, 1459 (2000), pp. 266-273

[3]

D.E. Canfield, A.N. Glazer, P.G. FalkowskiThe evolution and future of earth's nitrogen cycle

Science, 330 (2010), pp. 192-196

[4]

V. Calabrese, C. Cornelius, E. Rizzarelli, J.B. Owen, A.T. Dinkova-Kostova, D.A. ButterfieldNitric oxide in cell survival: a janus molecule

Antioxid. Redox Signal., 11 (2009), pp. 2717-2739

[5]

K.C. Wood, R.A. Alvarez, A.C. StraubChapter 18 - Diffusional control of nitric oxide in the vessel wall A2 - Ignarro, Louis J

B.A. Freeman (Ed.), Nitric Oxide ((Third Edition)), Academic Press (2017), pp. 237-246

[6]

F. Schreiber, P. Wunderlin, K.M. Udert, G.F. WellsNitric oxide and nitrous oxide turnover in natural and engineered microbial communities: biological pathways, chemical reactions, and novel technologies

Front. Microbiol., 3 (2012), pp. 1-24

$[7]$

H. Qi, C. Zhang, X. LiAmperometric third-generation hydrogen peroxide biosensor incorporating multiwall carbon nanotubes and hemoglobin

Sensors Actuators B Chem., 114 (2006), pp. 364-370

[8]

M. Baghayeri, H. Veisi, M. Ghanei-MotlaghAmperometric glucose biosensor based on immobilization of glucose oxidase on a magnetic glassy carbon electrode modified with a novel magnetic nanocomposite

Sensors Actuators B Chem., 249 (2017), pp. 321-330

[9]

S. Alim, A.K.M. Kafi, R. Jose, M.M. Yusoff, J. VejayanEnhanced direct electron transfer of redox protein based on multiporous $\mathrm{SnO}_{2}$ nanofibercarbon nanotube nanocomposite and its application in biosensing Int. J. Biol. Macromol., 114 (2018), pp. 1071-1076

E. Pashai, G. Najafpour Darzi, M. Jahanshahi, F. Yazdian, M. RahimnejadAn electrochemical nitric oxide biosensor based on immobilized cytochrome $c$ on a chitosan-gold nanocomposite modified gold electrode

Int. J. Biol. Macromol., 108 (2018), pp. 250-258 
A.A. Abdelwahab, W.C.A. Koh, H.-B. Noh, Y.-B. ShimA selective nitric oxide nanocomposite biosensor based on direct electron transfer of microperoxidase: removal of interferences by co-immobilized enzymes Biosens. Bioelectron., 26 (2010), pp. 1080-1086

E. Casero, M. Darder, F. Pariente, E. LorenzoPeroxidase enzyme electrodes as nitric oxide biosensors

Anal. Chim. Acta, 403 (2000), pp. 1-9

C.M. Cordas, A.G. Duarte, J.J.G. Moura, I. MouraElectrochemical behaviour of bacterial nitric oxide reductase-evidence of low redox potential non-heme Fев gives new perspectives on the catalytic mechanism

Biochim. Biophys. Acta, 1827 (2013), pp. 233-238

$\underline{\text { Article }}$

$[14]$

C.M. Cordas, A.S. Pereira, C.E. Martins, C.G. Timóteo, I. Moura, J.J.G. Moura, et al.Nitric oxide reductase: direct electrochemistry and electrocatalytic activity

ChemBioChem, 7 (2006), pp. 1878-1881

A.G. Duarte, C.M. Cordas, J.J.G. Moura, I. MouraSteady-state kinetics with nitric oxide reductase (NOR): new considerations on substrate inhibition profile and catalytic mechanism

Biochim. Biophys. Acta, 1837 (2014), pp. 375-384

S.J. Field, M.D. Roldan, S.J. Marritt, J.N. Butt, D.J. Richardson, N.J. WatmoughElectron transfer to the active site of the bacterial nitric oxide reductase is controlled by ligand binding to heme $\boldsymbol{b}_{\mathbf{3}}$

Biochim. Biophys. Acta, 1807 (2011), pp. 451-457

S. Ramos, R.M. Almeida, C.M. Cordas, J.J.G. Moura, S.R. Pauleta, I. MouraInsights into the recognition and electron transfer steps in nitric oxide reductase from Marinobacter hydrocarbonoclasticus

J. Inorg. Biochem., 177 (2017), pp. 402-411

N. Yang, X. Chen, T. Ren, P. Zhang, D. YangCarbon nanotube based biosensors

Sensors Actuators B Chem., 207 (2015), pp. 690-715 
S. Lata, C.S. PundirL-amino acid biosensor based on L-amino acid oxidase immobilized onto NiHCNFe/c-MWCNT/PPy/GC electrode

Int. J. Biol. Macromol., 54 (2013), pp. 250-257

[20]

J. Narang, N. Chauhan, P. Jain, C.S. PundirSilver nanoparticles/multiwalled carbon nanotube/polyaniline film for amperometric glutathione biosensor Int. J. Biol. Macromol., 50 (2012), pp. 672-678

[21]

R. Rawal, S. Chawla, P. Malik, C.S. PundirAn amperometric biosensor based on laccase immobilized onto $\mathrm{MnO}_{2} \mathrm{NPs} / \mathrm{cMWCNT/PANI}$ modified Au electrode

Int. J. Biol. Macromol., 51 (2012), pp. 175-181

$[22]$

L. Liu, C. Yang, K. Zhao, J. Li, H.-C. WuUltrashort single-walled carbon nanotubes in a lipid bilayer as a new nanopore sensor

Nat. Commun., 4 (2013), pp. 1-8

T. Mahmoudi-Badiki, E. Alipour, H. Hamishehkar, S.M. GolabiDopamineloaded liposome and its application in electrochemical DNA biosensor

J. Biomater. Appl., 31 (2016), pp. 273-282

C. Apetrei, P. Alessio, C.J.L. Constantino, J.A. de Saja, M.L. Rodriguez-Mendez, F.J. Pavinatto, et al.Biomimetic biosensor based on lipidic layers containing tyrosinase and lutetium bisphthalocyanine for the detection of antioxidants

Biosens. Bioelectron., 26 (2011), pp. 2513-2519

H. Guan, X. Liu, W. WangEncapsulation of tyrosinase within liposome bioreactors for developing an amperometric phenolic compounds biosensor J. Solid State Electrochem., 17 (2013), pp. 2887-2893

J. Liu, L. Han, T. Wang, W. Hong, Y. Liu, E. WangEnzyme immobilization and direct electrochemistry based on a new matrix of phospholipid-monolayerfunctionalized graphene

Chem. Asian J., 7 (2012), pp. 2824-2829 
C.M. Miyazaki, T.P. Pereira, D.B.T. Mascagni, M.L. de Moraes, M. FerreiraMonoamine oxidase $B$ layer-by-layer film fabrication and characterization toward dopamine detection

Mater. Sci. Eng. C, 58 (2016), pp. 310-315

Y. Tian, J. Xia, L. Zhang, J. Zhang, Y. Jiang, Y. Zhang, et al.Ionic liquid based polymeric liposomes: a stable and biocompatible soft platform for bioelectrochemistry

Bioelectrochemistry, 111 (2016), pp. 41-48

[29]

J. Yan, H. Guan, J. Yu, D. ChiAcetylcholinesterase biosensor based on assembly of multiwall carbon nanotubes onto liposome bioreactors for detection of organophosphates pesticides

Pestic. Biochem. Physiol., 105 (2013), pp. 197-202

$[30]$

M. Yoshimoto, C. Iida, A. Kariya, N. Takaki, M. NakayamaA biosensor composed of glucose oxidase-containing liposomes and $\mathrm{MnO}_{2}$-based layered nanocomposite

Electroanalysis, 22 (2010), pp. 653-659

Q. Liu, B.J. BoydLiposomes in biosensors

Analyst, 138 (2013), pp. 391-409

O.K. Nag, V. AwasthiSurface engineering of liposomes for stealth behavior Pharmaceutics, 5 (2013), pp. 542-569

P. Milla, F. Dosio, L. CattelPEGylation of proteins and liposomes: a powerful and flexible strategy to improve the drug delivery

Curr. Drug Metab., 13 (2012), pp. 105-119

P. Girsch, S. de VriesPurification and initial kinetic and spectroscopic characterization of NO reductase from Paracoccus denitrificans

Biochim. Biophys. Acta, 1318 (1997), pp. 202-216

Article

M. Prudêncio, A.S. Pereira, P. Tavares, S. Besson, I. Cabrito, K. Brown, et al.Purification, characterization, and preliminary crystallographic study of copper-containing nitrous oxide reductase from Pseudomonas nautica 617 Biochemistry, 39 (2000), pp. 3899-3907 
U.K. LaemmliCleavage of structural proteins during the assembly of the head of bacteriophage $\mathrm{T} 4$

Nature, 227 (1970), pp. 680-685

C.G. Timóteo, A.S. Pereira, C.E. Martins, S.G. Naik, A.G. Duarte, J.J.G. Moura, et al.Low-spin heme $\boldsymbol{b}_{3}$ in the catalytic center of nitric oxide reductase from Pseudomonas nautica

Biochemistry, 50 (2011), pp. 4251-4262

A. Akbarzadeh, R. Rezaei-Sadabady, S. Davaran, S.W. Joo, N. Zarghami, Y. Hanifehpour, et al.Liposome: classification, preparation, and applications Nanoscale Res. Lett., 8 (2013), pp. 1-9

S. Garny, N. Beeton-Kempen, I. Gerber, J. Verschoor, J. JordaanThe coimmobilization of P450-type nitric oxide reductase and glucose dehydrogenase for the continuous reduction of nitric oxide via cofactor recycling

Enzym. Microb. Technol., 85 (2016), pp. 71-81

S.L. BearneIllustrating the effect of pH on enzyme activity using Gibbs energy profiles

J. Chem. Educ., 91 (2014), pp. 84-90

M. Bhuvana, V. DharumanTethering of spherical DOTAP liposome gold nanoparticles on cysteamine monolayer for sensitive label free electrochemical detection of DNA and transfection

Analyst, 139 (2014), pp. 2467-2475

T. Hino, Y. Matsumoto, S. Nagano, H. Sugimoto, Y. Fukumori, T. Murata, S. Iwata, Y. ShiroStructural basis of biological $\mathbf{N 2 O}$ generation by bacterial nitric oxide reductase

Science, 330 (2010), pp. 1666-1670

M.E. Orazem, B. TribolletElectrochemical Impedance Spectroscopy

John Wiley \& Sons, New Jersey (2008)

T.M. Oliveira, M.F. Barroso, S. Morais, M. Araujo, C. Freire, P. de Lima-Neto, et al.Sensitive bi-enzymatic biosensor based on polyphenoloxidases-gold nanoparticles-chitosan hybrid film-graphene doped carbon paste electrode for carbamates detection 
Bioelectrochemistry, 98 (2014), pp. 20-29

$[45]$

G. Alarcon-Angeles, G.A. Álvarez-Romero, A. MerkoçiElectrochemical biosensors: enzyme kinetics and role of nanomaterials

Reference Module in Chemistry, Molecular Sciences and Chemical Engineering, Elsevier (2017)

[46]

S. Datta, L.R. Christena, Y.R.S. RajaramEnzyme immobilization: an overview on techniques and support materials

Biotech, 3 (2013), pp. 1-9

[47]

H. Yang, C. Gong, L. Miao, F. XuA glucose biosensor based on horseradish peroxidase and glucose oxidase co-entrapped in carbon nanotubes modified electrode

Int. J. Electrochem. Sci., 12 (2017), pp. 4958-4969

[48]

O. Matarredona, H. Rhoads, Z. Li, J.H. Harwell, L. Balzano, D.E. ResascoDispersion of single-walled carbon nanotubes in aqueous solutions of the anionic surfactant NaDDBS

J. Phys. Chem. B, 107 (2003), pp. 13357-13367

D.M. Byler, H. SusiExamination of the secondary structure of proteins by deconvolved FTIR spectra

Biopolymers, 25 (1986), pp. 469-487

W.K. Surewicz, H.H. MantschNew insight into protein secondary structure from resolution-enhanced infrared spectra

Biochim. Biophys. Acta, 952 (1988), pp. 115-130

J. Čeponkus, A.P. Smilga, I. Rumskaitè, I. Puodžiūtè, V. ŠablinskasInfrared absorption spectroscopy of functionalized single-walled carbon nanotubes Chem. Aust., 24 (2013), pp. 9-19

S.Y. Madani, A. Tan, M. Dwek, A.M. SeifalianFunctionalization of singlewalled carbon nanotubes and their binding to cancer cells

Int. J. Nanomedicine, 7 (2012), pp. 905-914

https://webbook.nist.gov/cgi/cbook.cgi?ID=C68122\&Type=IR-SPEC\&Index $=0$ (accessed on 23-12-2018) 
D. Grieshaber, R. MacKenzie, J. Vörös, E. ReimhultElectrochemical biosensors - Sensor principles and architectures

Sensors, 8 (2008), pp. 1400-1458

$[55]$

F. Wang, X. Chen, Y. Xu, S. Hu, Z. GaoEnhanced electron transfer for hemoglobin entrapped in a cationic gemini surfactant films on electrode and the fabrication of nitric oxide biosensor

Biosens. Bioelectron., 23 (2007), pp. 176-182

$[56]$

F.W.P. Ribeiro, F.W. de Souza Lucas, L.H. Mascaro, S. Morais, P.N. da Silva Casciano, $\mathrm{P}$. de Lima-Neto, et al.Electroanalysis of formetanate hydrochloride by a cobalt phthalocyanine functionalized multiwalled carbon nanotubes modified electrode: characterization and application in fruits

Electrochim. Acta, 194 (2016), pp. 187-198

$[57]$

M. Gamero, F. Pariente, E. Lorenzo, C. AlonsoNanostructured rough gold electrodes for the development of lactate oxidase-based biosensors

Biosens. Bioelectron., 25 (2010), pp. 2038-2044

$[58]$

H. Ole, J. Ulstrup (Eds.), Bioinorg. Chem., Springer Science \& Business Media (2007)

Y.-M. Li, H.-H. Liu, D.-W. PangDirect electrochemistry and catalysis of hemeproteins entrapped in methyl cellulose films

J. Electroanal. Chem., 574 (2004), pp. 23-31

[60]

L. Zhang, G.-C. Zhao, X.-W. Wei, Z.-S. YangA nitric oxide biosensor based on myoglobin adsorbed on multi-walled carbon nanotubes

Electroanalysis, 17 (2005), pp. 630-634

F.O. Gomes, L.B. Maia, C. Cordas, C. Delerue-Matos, I. Moura, J.J.G. Moura, S. MoraisNitric oxide detection using electrochemical third-generation biosensors - based on heme proteins and porphyrins

Electroanalysis, 30 (2018), pp. 1-20

F.L. Sousa, R.J. Alves, M.A. Ribeiro, J.B. Pereira-Leal, M. Teixeira, M.M. PereiraThe superfamily of heme-copper oxygen reductases: types and evolutionary considerations

Biochim. Biophys. Acta, 1817 (2012), pp. 629-637 
F.O. Gomes, L. Maia, C. Cordas, I. Moura, C. Delerue-Matos, J.J.G. Moura, S. MoraisElectroanalytical characterization of the direct Marinobacter hydrocarbonoclasticus nitric oxide reductase-catalysed nitric oxide and dioxygen reduction

Bioelectrochemistry, 125 (2019), pp. 8-14

L.M. Blomberg, M.R.A. Blomberg, P.E.M. SiegbahnReduction of nitric oxide in bacterial nitric oxide reductase - a theoretical model study

Biochim. Biophys. Acta, 1757 (2006), pp. 240-252

$[65]$

M.R.A. Blomberg, P.E.M. SiegbahnMechanism for $\mathbf{N}_{2} \mathbf{O}$ generation in bacterial nitric oxide reductase: a quantum chemical study

Biochemistry, 51 (2012), pp. 5173-5186

Y. ShiroStructure and function of bacterial nitric oxide reductases: nitric oxide reductase, anaerobic enzymes

Biochim. Biophys. Acta, 1817 (2012), pp. 1907-1913

J.P. Collman, Y. Yang, A. Dey, R.A. Decréau, S. Ghosh, T. Ohta, et al.A functional nitric oxide reductase model

Proc. Natl. Acad. Sci. U. S. A., 105 (2008), pp. 15660-15665

J.E. Dowd, D.S. RiggsA comparison of estimates of michaelis-menten kinetic constants from various linear transformations

J. Biol. Chem., 240 (1965), pp. 863-869

X. Chen, H.-Y. Long, W.-L. Wu, Z.-S. YangDirect electrochemical behavior of cytochrome $c$ on sodium dodecyl sulfate modified electrode and its application to nitric oxide biosensor

Thin Solid Films, 517 (2009), pp. 2787-2791

S. Jia, J. Fei, J. Deng, Y. Cai, J. LiDirect electrochemistry and electrocatalysis of hemoglobin immobilized in an amphiphilic diblock copolymer film Sensors Actuators B Chem., 138 (2009), pp. 244-250 
W. Wen, W. Chen, Q.-Q. Ren, X.-Y. Hu, H.-Y. Xiong, X.-H. Zhang, et al.A highly sensitive nitric oxide biosensor based on hemoglobinchitosan/graphene-hexadecyltrimethylammonium bromide nanomatrix Sensors Actuators B Chem., 166-167 (2012), pp. 444-450

F. Li, M. Nie, X. He, J. Fei, Y. Ding, B. FengDirect electrochemistry and electrocatalysis of hemoglobin on a glassy carbon electrode modified with poly(ethylene glycol diglycidyl ether) and gold nanoparticles on a quaternized cellulose support. A sensor for hydrogen peroxide and nitric oxide

Microchim. Acta, 181 (2014), pp. 1541-1549

$[73]$

A. Shrivastava, V. GuptaMethods for the determination of limit of detection and limit of quantitation of the analytical methods

Chro Cron. Young Sci., 2 (2011), pp. 21-25

X. Liu, L. Shang, Z. Sun, G. LiDirect electrochemistry of hemoglobin in dimethyldioctadecyl ammonium bromide film and its electrocatalysis to nitric oxide

J. Biochem. Biophys. Methods, 62 (2005), pp. 143-151

Y.-C. Liu, J. Zhao, W.-L. Wu, Z.-S. YangDirect electrochemical behavior of cytochrome $c$ on DNA modified glassy carbon electrode and its application to nitric oxide biosensor

Electrochim. Acta, 52 (2007), pp. 4848-4852

A.A. Abdelwahab, W.C. Koh, H.B. Noh, Y.B. ShimA selective nitric oxide nanocomposite biosensor based on direct electron transfer of microperoxidase: removal of interferences by co-immobilized enzymes Biosens. Bioelectron., 26 (2010), pp. 1080-1086

W.C. Alvin Koh, M.A. Rahman, E.S. Choe, D.K. Lee, Y.-B. ShimA cytochrome c modified-conducting polymer microelectrode for monitoring in vivo changes in nitric oxide

Biosens. Bioelectron., 23 (2008), pp. 1374-1381

R.M. Santos, M.S. Rodrigues, J. Laranjinha, R.M. BarbosaBiomimetic sensor based on hemin/carbon nanotubes/chitosan modified microelectrode for nitric oxide measurement in the brain Biosens. Bioelectron., 44 (2013), pp. 152-159 